\title{
The Role of Sirtuins in Antioxidant and Redox Signaling
}

\author{
Chandra K. Singh, Gagan Chhabra, Mary Ann Ndiaye, Liz Mariely Garcia-Peterson, \\ Nicholas J. Mack, and Nihal Ahmad
}

\begin{abstract}
Significance: Antioxidant and redox signaling (ARS) events are regulated by critical molecules that modulate antioxidants, reactive oxygen species (ROS) or reactive nitrogen species (RNS), and/or oxidative stress within the cell. Imbalances in these molecules can disturb cellular functions to become pathogenic. Sirtuins serve as important regulators of ARS in cells.

Recent Advances: Sirtuins (SIRTs 1-7) are a family of nicotinamide adenine dinucleotide (NAD)-dependent histone deacetylases with the ability to deacetylate histone and nonhistone targets. Recent studies show that sirtuins modulate the regulation of a variety of cellular processes associated with ARS. SIRT1, SIRT3, and SIRT5 protect the cell from ROS, and SIRT2, SIRT6, and SIRT7 modulate key oxidative stress genes and mechanisms. Interestingly, SIRT4 has been shown to induce ROS production and has antioxidative roles as well.

Critical Issues: A complete understanding of the roles of sirtuins in redox homeostasis of the cell is very important to understand the normal functioning as well as pathological manifestations. In this review, we have provided a critical discussion on the role of sirtuins in the regulation of ARS. We have also discussed mechanistic interactions among different sirtuins. Indeed, a complete understanding of sirtuin biology could be critical at multiple fronts.

Future Directions: Sirtuins are emerging to be important in normal mammalian physiology and in a variety of oxidative stress-mediated pathological situations. Studies are needed to dissect the mechanisms of sirtuins in maintaining redox homeostasis. Efforts are also required to assess the targetability of sirtuins in the management of redox-regulated diseases. Antioxid. Redox Signal. 28, 643-661.
\end{abstract}

Keywords: sirtuins, redox signaling, oxidative stress, antioxidants

\section{Introduction}

$\mathbf{T}$ HE SIRTUINS (SIRTs) are a family of nicotinamide adenine dinucleotide (NAD)-dependent histone deacetylases (HDACs) that have been identified and explored in mammals during the last two decades. Over the years, sirtuins have been shown to play key roles in many cellular functions, including histone deacetylation, protein acylation, and deacetylation (25). The sirtuin family of seven enzymes has also been linked to several antioxidant and oxidative stressrelated processes and functions, including longevity, mitochondrial function, DNA damage repair, and metabolism (105). In addition, the fact that their deacetylase activity is dependent on $\mathrm{NAD}^{+}$, a key redox signaling molecule, lends credence to the idea that sirtuins may be integral players in regulating cellular antioxidant and redox signaling (ARS) pathways. The coenzyme $\mathrm{NAD}^{+}$mediates redox reactions by carrying electrons from one reaction to another (i.e., $\mathrm{NAD}^{+}$, as an oxidizing agent, accepts an electron and converts into its reduced form, NADH, and vice versa). During metabolic activity, reduced compounds (glucose and fatty acids) are oxidized, resulting in a release of energy. As part of $\beta$-oxidation, glycolysis, and the Krebs cycle, this energy is transmitted via $\mathrm{NAD}^{+}$by reduction to $\mathrm{NADH}$. The $\mathrm{NAD}^{+} /$ NADH ratio is a key component of the redox state of a cell, which can indicate the status of the metabolism and health of cells (142). Although cells have many defensive mechanisms to maintain a fine balance between antioxidant and oxidant

Department of Dermatology, University of Wisconsin, Madison, Wisconsin. 
systems, improper biochemical reactions within the cell as well as certain external factors can throw the cell into a state of oxidative stress. As defined by Sies and Jones, oxidative stress is "an imbalance between oxidants and antioxidants in favor of the oxidants, leading to a disruption of redox signaling and control, and/or molecular damage" $(66,150)$. Some of the key players in oxidative stress are reactive species (RS), which most commonly include reactive oxygen species (ROS) and reactive nitrogen species (RNS). Many diseases and disorders have been linked with oxidant/antioxidant imbalance within the cells. Indeed, studies have suggested the role of sirtuins in regulating antioxidants and redox signaling pathways. The available literature seems to suggest that sirtuins are important in the homeostasis of redox systems, which may be critical in the regulation of important biological processes and, therefore, pathogenesis of several diseases. Thus, sirtuins may serve as targets in the management of redox-regulated disease conditions. This review is focused on critically analyzing the potential roles of sirtuins in redox regulation, oxidative stress, and ROS-induced conditions.

\section{Sirtuins: History and Discovery}

Mammalian SIRTs were discovered following extensive research conducted on the silent information regulator (SIR 1-4) genes, which were shown to be involved in transcriptional silencing in Saccharomyces cerevisiae (134). In 1999, Kaeberlein and McVey showed that overexpression of Sir2 extended life span in yeast (67). In 2000, a study by Imai et al. identified Sir2 as an NAD-dependent HDAC that deacetylates lysines 9 and 14 of histone $3(\mathrm{H} 3)$ and 16 of histone 4 (H4), suggesting that this histone modification ability may be a key to unlocking the connections between Sir2 and longevity, as well as metabolism, in yeast (61). The HDAC activity of sirtuins is important because histone acetylation and deacetylation are the key methods of gene regulation, and act via acetylating and deacetylating lysine residues of histone core of the nucleosome, thereby allowing or stopping the transcription of those genes in that area of the histone. Research conducted later showed sequence similarities in other organisms, from prokaryotes to eukaryotes, suggesting that sirtuins are highly conserved throughout evolution (49). Because of their HDAC activity, sirtuins have been categorized as HDACs, and their dependence on $\mathrm{NAD}^{+}$as a cofactor gave them a category of their own, Class III HDACs (44, 151). Seven members of this family have been identified so far in mammals, SIRTs 1-7, and each has a conserved NAD-binding and catalytic domain (although they differ in their $\mathrm{N}$ - and $\mathrm{C}$-terminal regions), termed as the sirtuin core domain (44). Interestingly, each sirtuin is primarily located in a distinct subcellular compartment, which is closely associated with the divergent biological functions within the cell [discussed below and reviewed in Ref. (94)].

Since their identification in mammals, sirtuins have been implicated in many important cellular processes, including facilitating heterochromatin formation, transcription silencing, regulation of ion channels, and modulation of cellular redox state (15). The initial insight into the roles of Sir2 in yeast led many researchers to study the role of mammalian sirtuins in metabolism and, to date, studies have suggested that these enzymes play crucial roles in insulin secretion, glycolysis, urea cycle, mitochondrial biogenesis, glucogenesis, and fat oxidation $(15,21,53,57,165)$. These roles, together with their NAD dependence, suggest that mammalian sirtuins could be important in maintaining cellular homeostasis via affecting cellular energetics and redox balance. The dependence on $\mathrm{NAD}^{+}$for their deacetylase activity allows sirtuins an ideal opportunity to regulate redox reactions via modulating transcription factors that control antioxidant enzyme expression and cellular $\mathrm{NAD}^{+} / \mathrm{NADH}$ ratios (131). Several target proteins of mammalian sirtuins have been identified as effectors of key oxidative stress pathways [reviewed in Refs. (93, 158, 173, 178)]. However, the specific mechanisms underlying the effects of each sirtuin on these effectors and on antioxidantdriven and redox signaling are an intense and interesting area of research.

\section{Reactive Oxygen and Nitrogen Species and Antioxidant Defense}

Molecular oxygen and its derivatives are absolutely vital to the living system. In the body, a variety of chemically reactive molecules that contain oxygen, as well as nitrogen and other elements, are essential for cellular signaling and biochemical processes. The primary forms of these RS in the cell include ROS such as hydrogen peroxide $\left(\mathrm{H}_{2} \mathrm{O}_{2}\right)$ and the superoxide anion radical $\left(\mathrm{O}_{2}{ }^{-}\right)$, the RNS nitric oxide (NO), as well as many peroxides of lipids, proteins, and nucleic acids $(87,175)$. These free radicals show very different reactivity, for example, superoxide is a reducing radical; reactivity of NO remains low unless it reacts with another free radical; $\mathrm{H}_{2} \mathrm{O}_{2}$, which is used extensively in ROS research, is less reactive than other ROS, but retains the ability to cause oxidative stress through the subsequent transformation to destructive moieties. On the contrary, secondary RS such as the hydroxyl radical $\left(\mathrm{HO}^{\bullet}\right)$ and peroxynitrite $\left(\mathrm{ONOO}^{-}\right)$are more toxic to the cell and generally form when an abundance of more than one primary RS is present (175).

$\mathrm{RS}$ are generated endogenously via numerous normal metabolic and biosynthetic pathways, including the respiratory chain, phagocytosis, prostaglandin synthesis, and the cytochrome P450 system (5, 6 and references therein). In addition, nonenzymatic cellular reactions can generate free radicals and ROS, for example, reactions between oxygen and organic compounds, as well as reactions initiated by ionizing radiation $(14,126)$. Normal biological levels of RS are necessary for spurring many critical reactions and signaling cascades [reviewed in Refs. $(6,127)]$. However, when generated in excess or combined with other RS, they can have serious deleterious effects on cellular constituents [reviewed in Refs. (54, 175)]. Therefore, to ensure the tight regulation of ROS and other RS levels, the cell has a myriad of antioxidant defenses available. Antioxidants generally function by one of two pathways: by either breaking the radical continuation chain or by preventing it from occurring completely (127). The major antioxidant enzymes such as superoxide dismutase (SOD), catalase (CAT), and glutathione peroxidase (GPX) prevent generation of the oxidation chain by scavenging the molecules responsible for generating free radicals (127, 185). Another important set of antioxidant enzymes, known as peroxiredoxins (PRDX) (which are regulated/activated by sulfiredoxin), controls cytokine-induced peroxide levels [reviewed in Ref. (24)]. Many studies have shown that dietary/ calorie restriction may have positive impacts on oxidative stress 
by decreasing the levels of ROS and increasing the activity of antioxidant enzymes [reviewed in Ref. (167)]. Interestingly, sirtuins gained their popularity, in part, due to their connections with calorie restriction-mediated beneficial health effects, including longevity [reviewed in Refs. $(53,93)$ ], suggesting that sirtuins may play an important role in regulating redox homeostasis.

The idea that sirtuins are involved in ARS also comes from their strong connections to several of the molecules of the antioxidant response element (ARE), which mediates signaling events involved in transcriptional regulation of gene expression in cells exposed to oxidative stress (Fig. 1). The ARE possesses biological and structural features that uniquely sense alteration of the cellular redox status and accordingly trigger transcriptional responses, mediated primarily by nuclear factor E2-related factor 2 (NRF2). NRF2 regulates the expression of several antioxidant and detoxification genes. NRF2 normally resides in the cytoplasm near Kelch like-ECHassociated protein 1 (KEAP1) and cullin 3 (CUL3), which degrade it by ubiquitination (76). Under oxidative stress, the KEAP1-CUL3 ubiquitination system is disrupted due to an interruption in critical cysteine residues of KEAP1. This allows NRF2 to translocate into the nucleus where it forms a heterodimer with one of the Maf proteins (MAFK, MAFG, MAFF) and binds to the ARE in the promoter region of antioxidative response genes resulting in initiation of their transcription $(62,114)$. Activation of NRF2 has also been shown to protect cells against cellular insults from electrophilic compounds. Once NRF2 is activated by electrophilic compounds, it translocates to the nucleus and binds to the electrophilic response element (ERE), which further modulates the expression of genes involved in the detoxication and elimination of electrophilic agents leading to enhancement in cellular antioxidant capacity (190). These ARE/ERE-controlled antioxidant enzymes and other antioxidants are important because, if left uncontrolled, oxidative stress can lead to various types of chronic conditions such as autoimmune, cardiovascular, and neurodegenerative diseases, cancer, aging, and acute ailments such as trauma and stroke (141).

In a very recent study on the regulation of cellular iron homeostasis, SIRT2 has been shown to deacetylate NRF2, resulting in a reduction in total and nuclear NRF2 levels (184). Moreover, SIRT2 has also exhibited the ability to regulate nuclear levels of NRF2 by modulating AKT phosphorylation, resulting modulation in the levels of total glutathione (GSH) and glutamate cysteine ligase (GCL), indicating SIRT2 may be a key modulator of this aspect of the ARE (23). SIRT1 also appears to be involved, as knockdown of SIRT1 has been shown to inhibit the expression of NRF2, heme oxygenase 1 (HO-1), and SOD1, eliminating the neuroprotective effects of SIRT1 induced by hyperbaric oxygen preconditioning against transient focal cerebral ischemia (182). Moreover, grape antioxidant resveratrol, which is considered to be an activator of SIRT1, has also been shown to modulate NRF2-dependent antioxidant protein expression to promote neuroprotection against cerebral ischemic injuries (109). SIRT6 has also been demonstrated to coactivate NRF2 to protect human mesenchymal stem cells (hMSCs) from oxidative stress (122). Interestingly, oxidative stress-related pathways appear to involve in the modulation of sirtuins as well affecting its activity, expression, posttranslational modifications, $\mathrm{NAD}^{+}$levels, and protein/protein interactions [reviewed in Ref. (140)]. Below, we have discussed the potential links between the sirtuins and ARS molecules, as well as how this knowledge may be used in the management of relevant diseases.

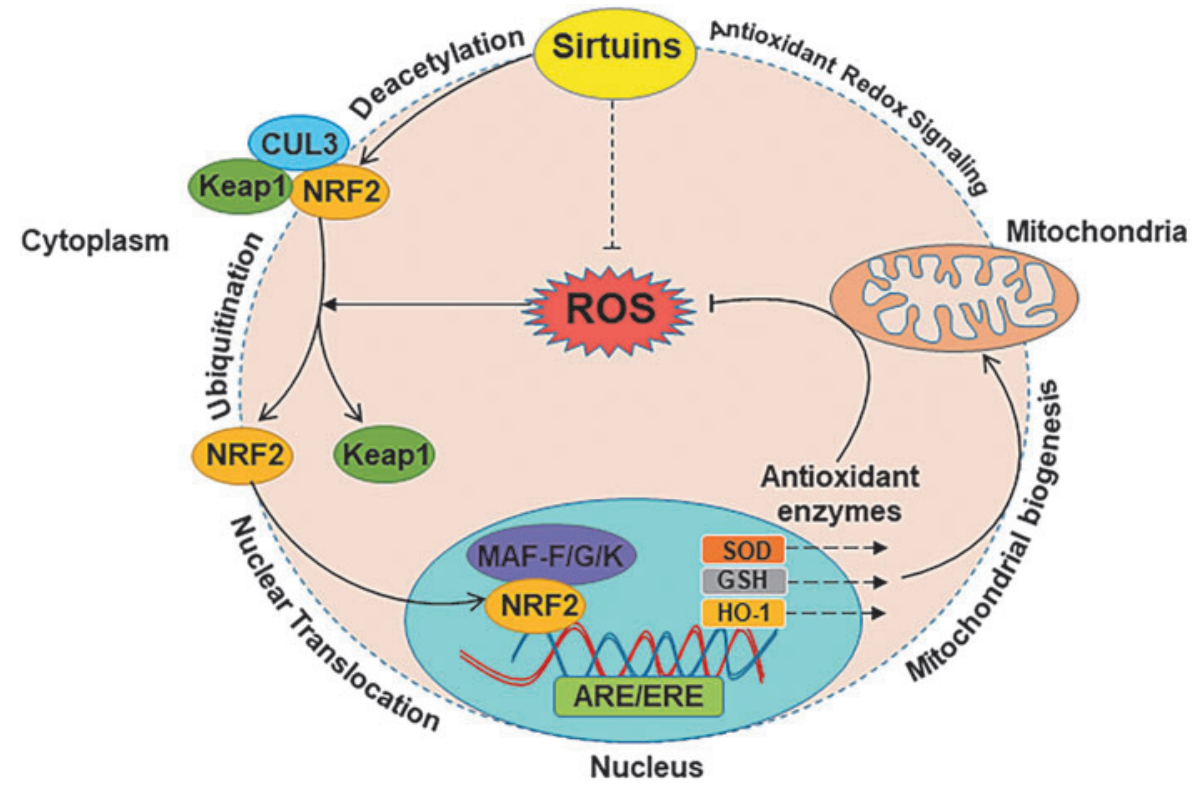

FIG. 1. Schematic representation showing interaction of sirtuins with NRF2 that regulates the expression of several antioxidant and detoxification genes. Under oxidative stress, the KEAP1-CUL3 ubiquitination system is disrupted, which allows NRF2 to translocate into the nucleus where it forms a heterodimer with one of the Maf proteins and binds to the ARE or ERE in the promoter region of antioxidative stress response genes resulting in mitochondrial biogenesis and antioxidant redox signaling. ARE, antioxidant response element; CUL3, cullin 3; ERE, electrophilic response element; GSH, glutathione; HO-1, heme oxygenase 1; KEAP1, kelch-like ECH-associated protein 1; NRF2, nuclear factor E2-related factor 2; ROS, reactive oxygen species; SOD, superoxide dismutase. 


\section{Sirtuins in Oxidative Stress Signaling}

From the available literature, it appears that all of the known mammalian sirtuins may be associated with oxidative stress signaling and antioxidant defense in the cell. A detailed account of individual sirtuins and their connection with redox regulation is provided below.

\section{SIRT1}

SIRT1 is the founding and most well-studied member of the mammalian sirtuin family. Although it has classically been thought to be of nuclear origin, multiple recent studies have shown SIRT1 to be localized to the cytoplasm as well $(8,176)$. SIRT1 has been shown to play important roles in development, cellular senescence, and cell death pathways [reviewed in Ref. (186)]. SIRT1 has also been shown to preferentially deacetylate lysine residue 9 of histone 3 (H3K9) and lysine 16 of histone 4 (H4K16) (61). SIRT1 initially gained its popularity because of studies suggesting its link with longevity and in calorie restriction $(21,53)$. However, its role in longevity has been widely debated due to lack of experimental repeatability, as well as inconsistencies between model systems (7, 18, 30, 48). Although the connection between SIRT1 and longevity is currently being widely investigated, its role in oxidative stress and redox signaling is much more clear and noncontroversial.

In two recent studies, synthetic small-molecule activators of SIRT1, SRT2104 and SRT1720, have been shown to extend life span, preserve bone and muscle mass, and improve the overall health of mice fed a standard diet $(92,98)$. One study found that SRT2104 treatment leads to reduced levels of protein carbonylation and formation of 4-hydroxynonenal (4-HNE) adduct, a marker of lipid peroxidation, in the liver and muscle, as well as increased SOD2 in muscles (92). This suggests that SIRT1 activation increases the antioxidant responses against age-dependent and ROS-mediated mitochondrial dysfunction in mice. It appears that this action of SIRT1 may be mediated by key redox-related transcription factors, including FOXO3a and p53. The FOXO (class O of forkhead box) family of transcription factors has been implicated in the regulation of a wide variety of genes related to antioxidant defenses [reviewed in Ref. (75)]. SIRT1 is known to deacetylate FOXO3a, which has been found to induce antioxidant responses via modulation in SOD2 and CAT (19, 55). FOXO3a has further been shown to regulate mitochondrial gene expression, resulting in modulated ROS levels (39). Although traditionally viewed as a tumor regulating protein, the key SIRT1 substrate, p53, has been found to have a fairly intricate regulative role in modulation of redox signaling [reviewed in Ref. (89)]. In nonstressed conditions, the transcription factor p53 is able to decrease intracellular ROS and increase certain antioxidant proteins, including SOD2 and GPX1, and downregulation of p53 has been shown to increase intracellular ROS levels and DNA oxidation levels (59, 138, 155). Moreover, Nemoto et al. demonstrated that SIRT1 regulates acetylation of PGC- $1 \alpha$, a master regulator of mitochondrial biogenesis (111). These regulatory pathway interactions suggest that SIRT1 is able to affect numerous cellular antioxidant defense mechanisms indirectly through the regulation of certain key effectors.

It appears that cellular oxidative stress may cause a dysregulation in normal SIRT1 functioning. It has been shown that in response to oxidative stress, SIRT1 is redistributed at the chromatin level causing deregulation at the transcription level (116). This study showed that $\mathrm{H}_{2} \mathrm{O}_{2}$ resulted in a significant modulation in a number of SIRT1-associated genes, including those involved in metabolism, apoptosis, ion transport, cell motility, and G protein signaling (116). Furthermore, SIRT1 was found to be required for DNA repair following $\mathrm{H}_{2} \mathrm{O}_{2}$-induced damage. This fits with another study showing that oxidative stress can trigger the dissociation of SIRT1 and the RNA-binding protein, HuR, which regulates the stability of several target messenger RNAs (mRNAs) (1). Under conditions of oxidative stress and DNA damage, HuR interacts with checkpoint kinase 2 (CHK2), leading to its dissociation from SIRT1 mRNA, activation of CHK2, and a shift by the cell toward apoptosis [(1) and reviewed in Ref. (17)]. Another enzyme required in the error-prone DNA repair pathway, poly (ADP-Ribose) polymerase 1 (PARP1), has been found to be activated in cells undergoing oxidative or genotoxic-induced senescence. This, in turn, leads to the reduction of NAD ${ }^{+}$availability and lower SIRT1 activity (45). The reduction in $\mathrm{NAD}^{+}$likely also has effects on other sirtuins, as well as cellular respiration, which can further contribute to oxidative stress. These complex interactions suggest that SIRT1 may be a key player in the mechanism responsible for maintaining homeostasis between DNA damage, senescence, and apoptosis under oxidative stress conditions.

In low oxygen conditions, the production of $\mathrm{O}_{2}^{-}$is increased by the respiratory chain (104). The elevated superoxide anions are converted to $\mathrm{H}_{2} \mathrm{O}_{2}$ via reaction of SOD with $\mathrm{O}_{2}{ }_{2}^{-}$in the mitochondrial matrix, which eventually leads to gene transcription that allows the cell to respond to the low oxygen levels (143). In a 2009 study, $\mathrm{H}_{2} \mathrm{O}_{2}$-induced oxidative stress was shown to downregulate SIRT1 dose and time dependently in keratinocytes (22). Moreover, treatment with the SIRT1 activator resveratrol was shown to prevent $\mathrm{H}_{2} \mathrm{O}_{2}$ induced cell death, decrease cell proliferation, and suppress senescence. Alternatively, the SIRT1 inhibitors sirtinol and nicotinamide were found to enhance $\mathrm{H}_{2} \mathrm{O}_{2}$-induced cell death (22, 60). Collectively, these data suggest that SIRT1 is a crucial player in the prevention of oxidative damage via a variety of mechanisms (Fig. 2).

\section{SIRT2}

Similar to other members of the sirtuin family, SIRT2 is found ubiquitously throughout the body. However, it appears to be expressed especially in organ systems relevant to metabolism, including the brain, kidneys, pancreas, testes, liver, and fat tissue in mice (47). SIRT2 mainly localizes in the cytoplasm, where it deacetylates $\alpha$-tubulin. However, SIRT2 is also found in the nucleus where it deacetylates H4K16 and takes part in regulating the cell cycle (48). Furthermore, SIRT2 has been shown to play a role in the development of the nuclear envelope, likely via deacetylation of ANKLE2, which is known to regulate reassembly of the nuclear envelope (68). Like other sirtuins, SIRT2 detects fuel in the cell, and it has been shown that its activity and expression are changed depending on the energy state of the cell: activated in low-energy status and repressed in high-energy status (47). This suggests an overlap in roles for SIRT2 in metabolism and cellular homeostasis.

Studies have shown that targets of SIRT2 deacetylation have important roles in antioxidant- and redox-mediated 


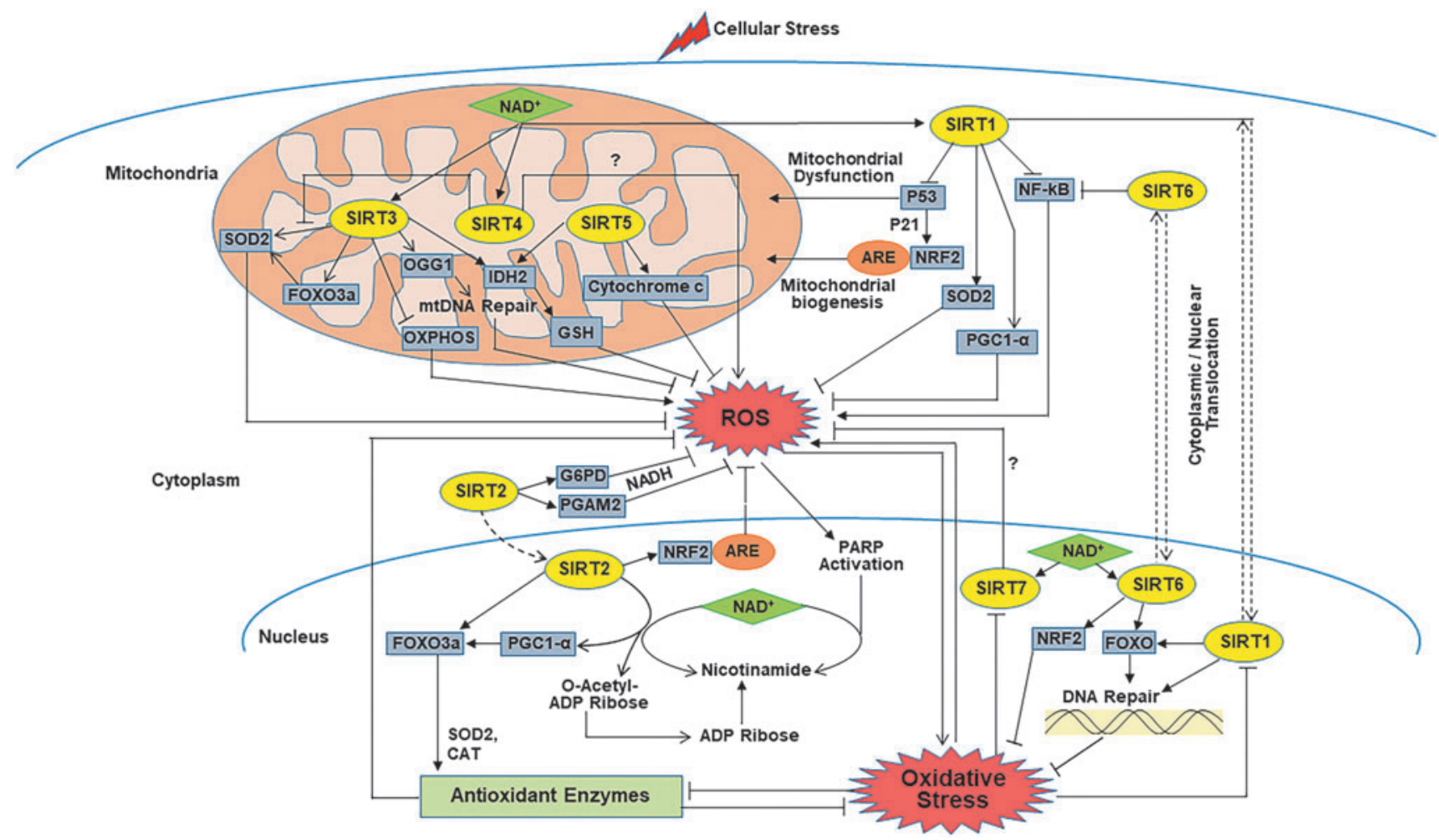

FIG. 2. Mechanistic illustration of the sirtuins in ARS pathways. Sirtuins are involved in regulating ARS in numerous ways. SIRTs 1-7 have been found to be involved in modulating levels of ROS, antioxidant enzymes, DNA repair, mitochondrial dysfunction, and oxidative stress in the cell through key transcription factors such as NRF2, p53, NF- $\kappa \mathrm{B}, \mathrm{FOXO}$, and PGC- $1 \alpha$. Question marks (?) indicate that exact mechanism is unknown. When cells become stressed, ROS production is increased, and coenzyme $\mathrm{NAD}^{+}$(green diamond) activates various sirtuins (yellow ovals). In addition, sirtuins regulate the activity of the ARE (orange ovals), which in turn modulates the transcription of pro- and antioxidant genes to maintain redox signaling cascades. ADP, adenosine diphosphate; ARS, antioxidant and redox signaling; CAT, catalase; FOXO, class O of forkhead box transcription factors; G6PD, glucose 6-phosphate dehydrogenase; NAD, nicotinamide adenine dinucleotide; NF- $\kappa \mathrm{B}$, nuclear factor kappa B subunit; PARP1, poly (ADP-ribose) polymerase 1; PGAM2, phosphoglycerate mutase; SIRT, sirtuin.

cellular homeostasis [reviewed in Ref. (47)]. One of these targets, PGC- $1 \alpha$, is deacetylated by SIRT2, which thereby modulates mitochondrial biogenesis and has been associated with upregulation of antioxidant enzyme expression and a reduction in ROS levels (77). SIRT2 has also been shown to deacetylate FOXO3a in response to oxidative stress, which is helpful because FOXO3a is a transcriptional activator of the SOD2 gene that encodes MnSOD protein, a powerful antioxidant (168).

Other targets of SIRT2, which also play a role in ROS mediation, are metabolic enzymes such as glucose 6phosphate dehydrogenase (G6PD), phosphoglycerate mutase (PGAM2), and nuclear factor kappa B subunit (NF- $\kappa$ B) (47). Under oxidative stress conditions, SIRT2 has been shown to deacetylate and activate G6PD, a key enzyme in the pentose phosphate pathway that produces NADPH in the cytosol (171). NADPH is an essential molecule that counteracts oxidative damage by keeping GSH in its reduced form. In the cell, GSH scavenges unsafe oxidative metabolites by converting $\mathrm{H}_{2} \mathrm{O}_{2}$ to water with the help of GPX [reviewed in Ref. (90)]. Interestingly, NADPH is the final reductant for PRDX, and SIRT2 has been shown to deacetylate and inhibit the peroxidase activity of PRDX-1, thereby sensitizing breast cancer cells to oxidative stress-inducing agents (42). Oxidative stress conditions also lead to deacetylation and activation of PGAM2 by SIRT2, which allows the cell to respond to stress more easily (181). In addition, SIRT2 has been shown to activate NF- $\kappa \mathrm{B}$, which plays an important role in regulating ROS in the cell (121). Regulation of ROS by NF- $\kappa \mathrm{B}$ is a complex process. The transcription of several NF- $\kappa \mathrm{B}$ dependent genes has been shown to influence the levels of ROS in the cell and, in turn, NF- $\kappa \mathrm{B}$ activity has also been shown to be regulated by the levels of ROS [reviewed in Ref. (99)]. NF- $\kappa$ B plays a dual role in regulating ROS by targeting enzymes that promote the production of ROS, such as NADPH oxidase, xanthine oxidoreductase, inducible NO synthase, cyclooxygenase- 2 , and cytochrome p450 enzymes. On the contrary, NF- $\kappa \mathrm{B}$ also targets those enzymes that may contribute to inhibition of ROS, such as SODs 1 and 2, thioredoxins, and glutathione S-transferase (99). Collectively, this suggests that SIRT2 has a critical role in the modulation of the oxidative stress response, implicating SIRT2 in the protection of organisms from metabolic disruption through mechanisms dependent on oxidative stress (Fig. 2).

\section{SIRT3}

SIRT3 is designated as a mitochondrial sirtuin since its active form is localized in the mitochondria. Full-length SIRT3 resides in the nucleus but translocates to the 
mitochondria in response to stress (e.g., DNA damage), where it is cleaved at its active site by the mitochondrial matrix processing peptidase (63). Although much of the research done on SIRT3 focuses on the roles played within the mitochondria, this enzyme has been implicated in a wide range of diseases, including cardiovascular, renal, and neurodegenerative diseases, as well as cancer $(46,58,118,125$, 139). Recent studies indicate that SIRT3 modulates mitochondrial metabolism and works together with SIRT1 to increase the life span of experimental animals. In fact, SIRT3 is the only member of the sirtuin family for which direct evidence exists regarding the increase of longevity in humans [reviewed in Ref. (48)]. As SIRT3 is a mitochondrial sirtuin and most of the conditions mentioned above are intimately tied with oxidative stress, it seems reasonable to assume that there may be numerous links between SIRT3 and oxidative stress.

Based on a number of studies, SIRT3 is known to mediate the flow of mitochondrial oxidative pathways and therefore regulate the production of ROS [reviewed in Ref. (166)]. Loss of SIRT3 has been shown to increase the production of ROS, which leads to stabilization of the protumorigenic transcription factor HIF- $1 \alpha$ (41). Furthermore, a study by Bell et al. found that increased ROS, in the absence of SIRT3, led to increased HIF- $1 \alpha$ activation, and SIRT3 knockdown was associated with increased tumor growth in mouse xenografts in an HIF- $1 \alpha$-dependent manner (13). This illustrates that SIRT3 is able to inhibit HIF- $1 \alpha$ as well as prevent ROSmediated genomic instability, suggesting that SIRT3 may have tumor suppressive capabilities through ROS modulation pathways. In addition to its potential roles in tumorigenesis, SIRT3 can affect cellular health directly by influencing the production of ROS through modulation of enzymes involved in the mitochondrial oxidative phosphorylation (OXPHOS) pathway (51). Human mitochondrial DNA (mtDNA) encodes for 13 proteins, which are known to have a role in regulating respiration and OXPHOS in the mitochondria, and is significantly more susceptible to oxidative damage than nuclear DNA $(133,146)$. In the cell, ROS generated by OXPHOS, ionizing radiation, or chemicals are responsible for DNA damage, including changing purine and pyrimidine bases to 8-oxo-7,8-dihydroguanine (8-oxoG). Importantly, SIRT3 has been shown to target the enzyme that repairs this DNA damage, human 8-oxoguanine-DNA glycosylase 1 (OGG1) (32). SIRT3 has been shown to promote OGG1 by physically binding to it to prevent degradation and control its activation when DNA glycosylase becomes active. In addition, SIRT3 has been found to be crucial in the repair of mtDNA, protecting the integrity of mitochondria, and protecting the cell from apoptosis under conditions of oxidative stress by mediating the activity and replenishment of OGG1 (32). Together, these results suggest that SIRT3 has an important role in protecting the cell against genotoxic stress and oxidative damage, underlining its importance in ARS.

SIRT3 has also been shown to mediate the deacetylation of enzymes that are responsible for the reduction of ROS, leading to protection against oxidative stress-dependent developments and disorders such as cardiac hypertrophy and dysfunction, cancer, aging, and neural degeneration [reviewed in Ref. (4)]. For example, SIRT3 has been shown to activate isocitrate dehydrogenase (IDH2), SOD2, and CAT, all key enzymes in reducing the cellular burden of ROS (93,
154, 156). In addition, SIRT3 knockout mice have been found to have impaired ROS regulating capabilities and endothelial function when fed a high-cholesterol diet, suggesting an important role in ROS, especially in endothelial cell function (177). Interestingly, increased levels of ROS have been found to stimulate SIRT3 transcription and thereby may lead to deacetylation of SOD2 through an oxidative stress feedback loop [discussed in Ref. (93)]. For example, decreased SIRT3 levels have been found in human epidermal keratinocytes after ozone exposure, which was correlated with increased DNA damage, higher levels of cellular $\mathrm{H}_{2} \mathrm{O}_{2}$, and reduced SOD2 protein levels (91). This is important because lack of regulation of ROS in keratinocytes, which form and maintain the protective layer of the skin, is known to have an impact on their differentiation. When SIRT3 is knocked down in keratinocytes, levels of $\mathrm{O}_{2}^{-}$increase, promoting differentiation markers. The opposite is seen in keratinocytes with forced overexpression of SIRT3, which have decreased $\mathrm{O}_{2}{ }_{2}^{-}$levels and expression of differentiation markers (11).

SIRT3 has been found to have roles in cellular metabolism as well. SIRT3 has also been found to modulate mitochondrial function by mediating levels of $\mathrm{NAD}^{+}$, which can protect the liver and kidneys from acute diseases and injuries $(71,100)$. One study conducted on mice lacking SIRT3 found that compared to normal mice, the SIRT3 knockout mice exhibited decreased oxygen consumption, as well as an increase in ROS (65). These observations were also further confirmed through the knockout of SIRT3 in vitro using myoblasts, suggesting that the link between SIRT3 and cellular energy levels needs to be further explored. Taken together with SIRT3's obvious role in protecting cells from oxidative damage and genotoxic stress, these studies suggest the possible involvement of SIRT3 in multiple pathways associated with the regulation of oxidative stress (also outlined in Fig. 2).

\section{SIRT4}

SIRT4 is a mitochondrial sirtuin with the main function of ribosylation of adenosine diphosphate (ADP) $(3,48)$. It has been found to be highly expressed in the heart, kidneys, liver, and brain, suggesting that it may have enhanced roles in these tissues (52). Unlike other sirtuins, SIRT4 was initially thought to not have $\mathrm{NAD}^{+}$-dependent deacetylase activity. Instead, it had been shown to use NAD to ADP-ribosylate glutamate dehydrogenase, which converts glutamate to $\alpha$ ketoglutarate in mitochondria (52). Recently, however, SIRT4 was found to have the ability to deacetylate lysine, allowing it to control leucine metabolism and insulin secretion (3). In this study, SIRT4 knockout mice were shown to have dysregulated leucine metabolism, leading to elevated insulin secretion (3). This may be responsible for the mice developing accelerated age-induced resistance to insulin. Furthermore, a plethora of studies suggest that all the sirtuins except SIRT4 play a key role in the reduction of mitochondrial oxidative stress throughout the caloric restriction process [reviewed in Refs. $(148,172)$ ]. This, however, does not minimize the role played by SIRT4 in oxidative stress regulation in the cell.

SIRT4 has been shown to be involved in the regulation of ROS production in mitochondria (Fig. 2), although it is 
unclear if it affects the activation of antioxidant enzymes localized to the mitochondrial matrix. In a study of angiotensin II (Ang II)- induced cardiac hypertrophy in mice, it was found that overexpression and knockout of SIRT4 increased and decreased ROS, respectively, in both the heart and mitochondria (86). These same results were observed in rat cardiomyocytes, suggesting that SIRT4 may directly control the production of ROS to some extent in heart cells. The authors also found that SIRT4 inhibited the binding of SOD2 to SIRT3, resulting in increased acetylation and thereby reduced the activity of SOD2 (86). Together, these results suggest that SIRT4 may play an important role in managing the players involved in the antioxidant response, if not in actual regulation of the gene themselves.

Also, SIRT4 has been shown to be an integral factor in fatty acid oxidation in the liver and in muscle cells. A 2010 study found that SIRT4 knockdown increased fatty acid oxidation and oxygen consumption in primary mouse hepatocytes, possibly via regulating SIRT1 expression (110). This is important because oxidation of fatty acids is a key source of mitochondrial ROS and has been linked to certain diseases, including kidney damage in diabetes (135). Interestingly, because of its role in oxidative metabolism, SIRT4 is being explored as a biomarker for coronary artery disease for certain populations. A 2014 study found that obese patients with hepatic steatosis had significantly lower levels of circulating SIRT4 than normal controls (157). The authors theorized that the lower SIRT4 levels may be in response to the lack of exercise and a high-calorie diet (both factors in increasing oxidative stress in many mammals) to reduce mitochondrial ROS, but this does not appear to fit with the previous research (110). It remains to be seen if SIRT4 can serve as a biomarker for coronary artery disease and what the exact role played by this sirtuin is. Also, the expression of SIRT4 has been found to differ depending on the cell type, which will need to be taken into consideration before using as a biomarker for

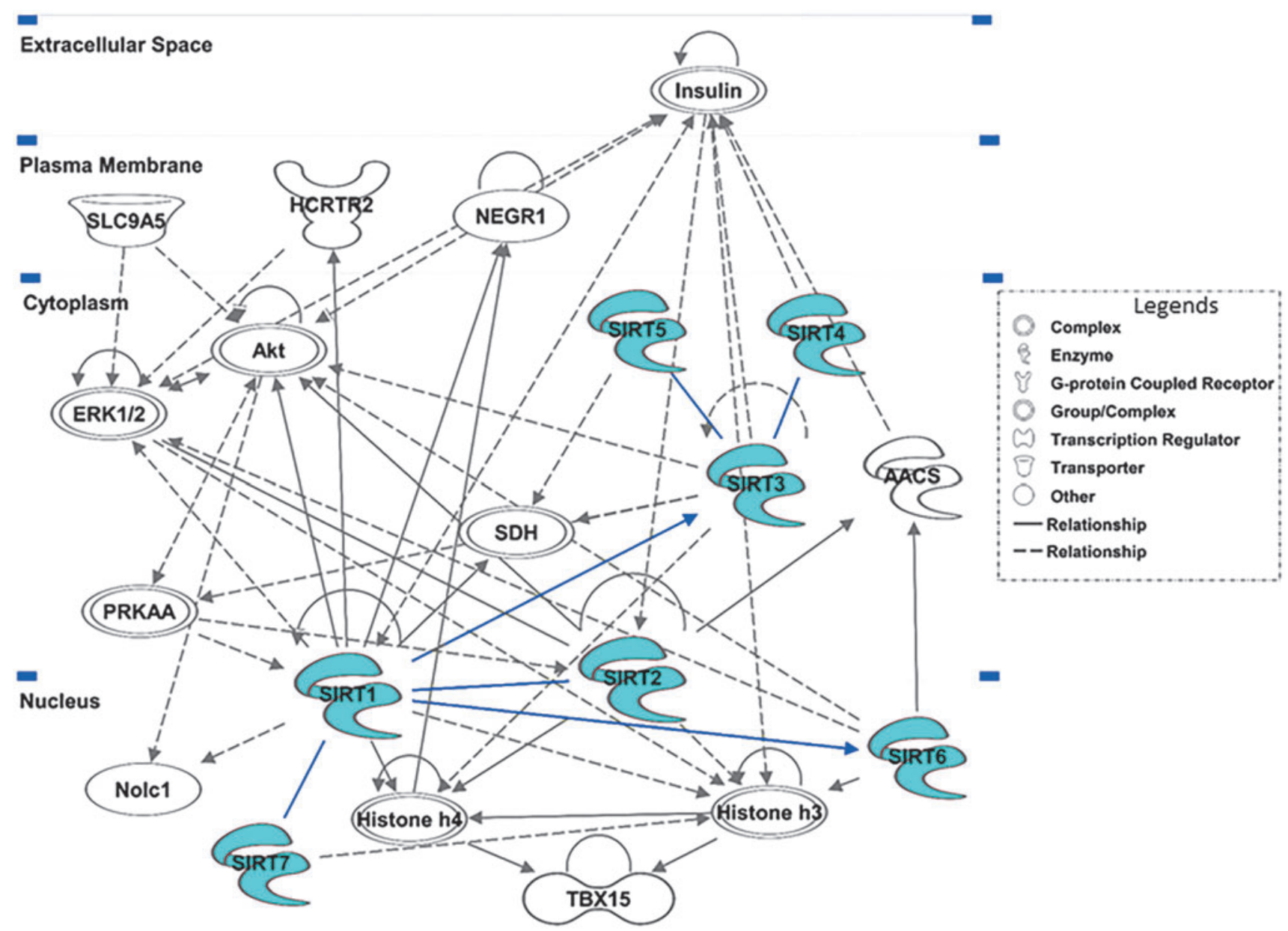

FIG. 3. Dynamic interaction network of sirtuins. A sirtuin interaction network was generated via Ingenuity Pathway Analysis (QIAGEN) to highlight how sirtuins interact among themselves. Molecular interactions are denoted by arrows with solid lines showing robust correlation and dashed lines showing less frequent correlations. In addition to SIRTs 1-7, several other proteins have also appeared as mediators in the sirtuin network (indicated with uncolored background). Bluntended lines indicate protein/protein interactions and arrowed lines indicate that one is affecting the expression of other. The interactions among sirtuins are denoted with blue lines. The illustration shows that sirtuins closely interact with each other, either directly or through very few intermediaries. This network suggests that the network of ARS molecules may be impacted by more than one sirtuin, and that understanding the interplay between sirtuins is crucial to understand sirtuinmediated redox homeostasis. AACS, acetyl-CoA synthetase. 
specific diseases. Clearly, additional studies are needed to determine the full capabilities and actions of SIRT4 in antioxidant response and oxidative stress as well as in oxidative stress-associated disease conditions.

\section{SIRT5}

SIRT5 is also localized in the mitochondria, where it functions to deacetylate, demalonylate, and desuccinylate multiple proteins $(38,48)$. SIRT5 has been found to be highly expressed in the tissues of the brain, heart, liver, and lymphoblasts, where it is shown to be accumulated heavily in the intermembrane spaces of the mitochondria $(85,107)$. SIRT5 has been described to have roles in cellular metabolism, detoxification, regulation of oxidative stress, energy production, and mediation of the apoptosis pathway (82). However, there is no definitive consensus on the roles of SIRT5 in these processes, and many conflicting views seem to exist in this regard. Although more research is needed to determine the exact roles played by SIRT5, it appears that its association with ROS and oxidative stress signaling is strong (Fig. 2).

SIRT5 is popularly known for the regulation of mitochondrial fatty acid oxidation, the urea cycle, and cellular respiration (106, 183). SIRT5 deacetylates and activates carbamoyl phosphate synthetase (CPS1), which catalyzes the first step of the urea cycle for the detoxification of ammonia. SIRT5 knockout mice have shown to have increased levels of ammonia during fasting (106). Ogura et al. have shown that mice overexpressing SIRT5 have increased the activity of CPS1, facilitating the conversion of ammonia to nontoxic urea (117). Here, it is important to mention that ammonia is known to induce ROS production and decrease antioxidant GSH content (16), suggesting the indirect involvement of SIRT5 in managing oxidative stress.

Interestingly, Liu et al. have shown that SIRT5 protects cardiomyocytes from oxidatively induced apoptosis, although the mechanism by which this protection occurs is unclear (82). Recent data have identified suppression of oxidative stress as being a possible mechanism by which SIRT5 may protect against apoptosis in SH-EP neuroblastoma cells (80). This finding is in accordance with previous data in lung tumor and epithelial cells $(81,170)$. Lin et al. have shown that SIRT5 binds to and desuccinylates SOD1, and that desuccinylation increases SOD1 activity. Furthermore, SOD1mediated reduction in ROS was increased when SIRT5 was coexpressed, revealing a posttranslational regulation of SOD1 in lung tumor cells (81). SIRT5 has also been shown to deacetylate cytochrome $\mathrm{c}$, which is an essential component of the electron transport chain (145). In a very recent study, cells that were transfected with SIRT5 were found to have decreased levels of ROS, suggesting that SIRT5 suppresses the progression of oxidative stress conditions in the cell (80). Overall, it appears that SIRT5 plays important roles in a response of cells to oxidative stress. However, this area of research needs further efforts aimed at elucidating the exact mechanism of SIRT5 functions.

\section{SIRT6}

SIRT6 is located within the nucleus of the cell and has been shown to function through $\mathrm{NAD}^{+}$-dependent deacetylation of lysines 9 and 56 on histone 3 (H3K9 and H3K56) (95-97, 159, 160, 164). The delineation of SIRT6-mediated deacetylation on histone 3 uncovered the roles it possessed in chromatin regulation and gene expression through recruitment of certain transcription factors such as NF- $\kappa \mathrm{B}(69,70,188)$. In addition to playing important roles in chromatin regulation and recruitment of transcription factors such as NF- $\kappa \mathrm{B}$, SIRT6 has also been suggested to have critical functions in other cellular processes such as gene expression, glucose homeostasis, and DNA repair $(40,64,94,160,161)$. Research on SIRT6 knockout mice has provided the first evidence that it may be involved in regulating mammalian aging [reviewed in Ref. (48)]. SIRT6 knockout mice displayed shortened life span as well as premature aging phenotypes, including decrease in serum glucose and insulin-like growth factor (IGF-1) levels (103). Due to the essential roles SIRT6 has in cellular homeostasis, disruption of this enzyme appears to produce an effect on disease development $(12,53,57,101,136,161)$.

Based on recent research, SIRT6 is believed to be an important metabolic sensor that connects environmental signals to metabolic homeostasis and stress responses in mammals $(12,169)$. This underlines the role of SIRT6 as a mediator of oxidative stress and myocardial injury during ischemia/ reperfusion (I/R) (169). SIRT6 overexpression has been shown to protect cardiomyocytes against I/R injury by the reduction of oxidative stress and upregulation of endogenous antioxidants via an energy-sensing AMPK-FOXO3 $\alpha$ axis that is necessary for oxidative stress resistance (169). Thus, SIRT6 appears to be vital in redox and antioxidant homeostasis as it seems to aid against oxidative stress damage. Similarly, SIRT6 has been shown to protect hMSCs from oxidative stress through coactivation of NRF2 (122). SIRT6-null hMSCs were shown to have dysregulated redox metabolism resulting in increased sensitivity to oxidative stress. It was also suggested that SIRT6 serves as a coactivator of NRF2 via interactions with the RNA polymerase II (RNAP II) complex in such a way that reduction of SIRT6 in hMSCs decreases the activation of the RNAP II complex (122). In addition, SIRT6 and NF- $\kappa$ B have also demonstrated protective roles in high glucosemediated endothelial senescence (33). Downregulation of SIRT6 during a short-term exposure to high glucose increased expression of NF- $\kappa \mathrm{B}$, while overexpression of SIRT6 decreased NF- $\kappa \mathrm{B}(9)$. Interestingly, research has shown that the protective effects of the antioxidant ergothioneine are associated with increases in SIRT1 and SIRT6, and their negative regulation of $\mathrm{NF}-\kappa \mathrm{B}$, suggesting a strong dynamic regulation of both sirtuins in relation to redox signaling (33). SIRT6 has also been implicated in the control of inflammatory pathways in diabetic atherosclerotic lesions and endothelial levels (83). Moreover, epigenetic mechanisms in which stress represses SIRT6 expression have led to histone acetylation and gene expression, indicating a key role of SIRT6 in the stress response (187). Overall, SIRT6 expression and function seem to overlap with antiglycolytic and antioxidant mechanisms to aid against ROS (56) (Fig. 2). Indeed, our knowledge regarding the role and relevance of SIRT6 in oxidative stress and associated disease conditions is emerging and further research is needed in this direction.

\section{SIRT7}

The last member of the currently identified mammalian sirtuin family, SIRT7, is also primarily localized to the nucleus. Specifically, it is expressed in the nucleoli, where it binds to 


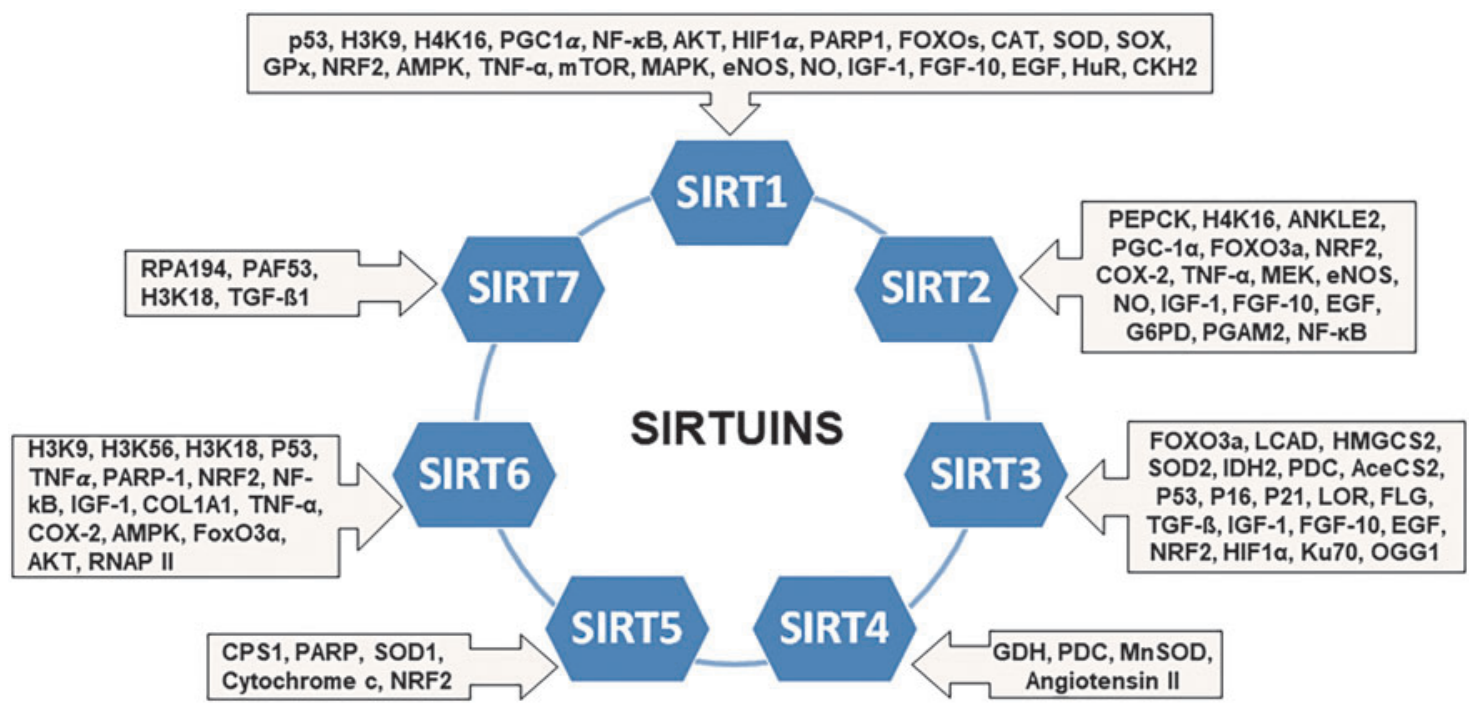

FIG. 4. Molecular associations of sirtuins with ARS-related targets. The figure illustrates the wide variety of ARSrelated targets that have been shown to be regulated with sirtuins. Interestingly, several of the proteins appear to have common targets for SIRTs 1-7. For example, NRF2 appears to be a common target for SIRTs 1-3, 5, and 6, to mediate antioxidative genes. The large number of targets identified for SIRT1 suggests it may be more involved in ARS regulation than other sirtuins, although it may be a by-product of its popularity in research and early identification instead.

histones to positively regulate ribosomal DNA (rDNA) transcription [reviewed in Ref. (48)]. SIRT7 mRNA has been found to be expressed differentially in all tissues, with more expression in those with higher metabolic activities, and decreased expression has been correlated with age [reviewed in Refs. (43, 73)]. Interestingly, SIRT7 knockout mice have been characterized by lethal heart hypertrophy and a progeroid phenotype, manifesting as premature physiological aging, making affected individuals appear to be older than they are (163). This suggests that SIRT7 may have a role in aging and/or age-related dis- eases. It is possible that these expression patterns and phenotypes are due to SIRT7's role in rDNA transcriptional regulation.

During replicative senescence, SIRT7 has been found to migrate to the chromatin and cytoplasm from the nucleoli, where it may reduce rDNA transcription (74). SIRT7 overexpression has shown to increase RNA polymerase I (RNA Pol I)-mediated transcription, while knockdown or inhibition of SIRT7 decreases it (43). This appears to be due to its ability to regulate subunits of RNA Pol I, specifically

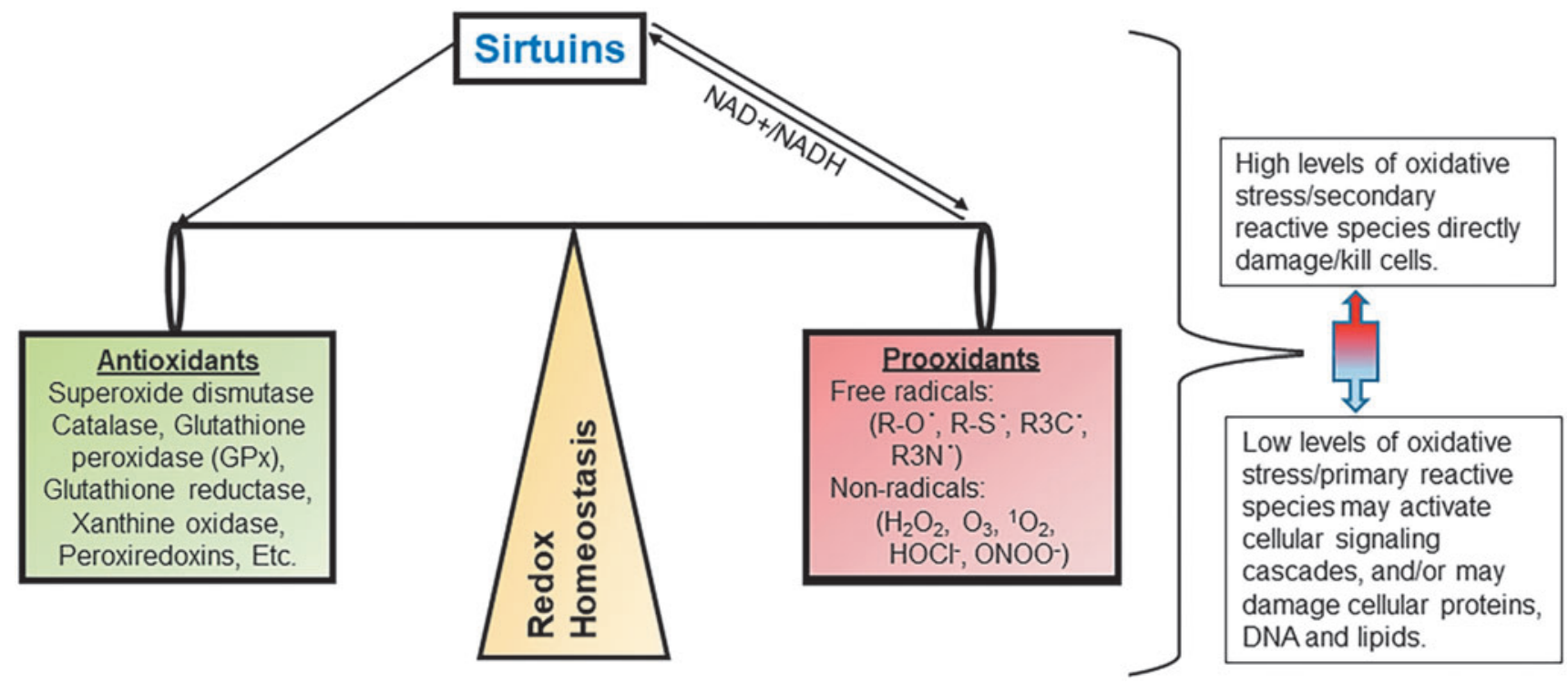

FIG. 5. A schematic representation of sirtuin-mediated redox homeostasis. Sirtuins contribute to redox homeostasis maintenance by balancing antioxidant enzymes and pro-oxidant radicals. As illustrated, sirtuins regulate the expression and activity of antioxidative enzymes and the production of pro-oxidants as well. Pro-oxidants also affect the activity of sirtuins through alteration of the $\mathrm{NAD}^{+} / \mathrm{NADH}$ ratio, allowing for a feedback loop that helps prevent the cell from entering or maintaining a state of oxidative stress. NAD, nicotinamide adenine dinucleotide. 
Table 1. Chemical Modulators of Sirtuins

\begin{tabular}{|c|c|c|}
\hline Modulators & Known actions & Ref. \\
\hline \multicolumn{3}{|l|}{ SIRT1 } \\
\hline Asiatic acid & $\begin{array}{l}\text { Increases SIRT1 and PGC-1, decreases apoptosis and ROS, } \\
\text { stabilizes mitochondrial membrane potential in human } \\
\text { neuroblastoma cells. }\end{array}$ & $(180)$ \\
\hline Baicalin & $\begin{array}{l}\text { Upregulates SIRT1, reduces LDH, NO, caspase-3, and } \\
\text { the apoptotic percentage of SH-SY5Y cells. }\end{array}$ & $(26)$ \\
\hline Exendin-4 & $\begin{array}{l}\text { Increases expression of SIRT } 1 \text { and AMPK in vivo; induces } \\
\text { fatty acid oxidation and glucose metabolism genes. }\end{array}$ & $(79)$ \\
\hline Ginkgolide B & $\begin{array}{l}\text { Increases expression of SIRT1 in oxidized low-density } \\
\text { lipoprotein-treated endothelial cells. }\end{array}$ & $(88)$ \\
\hline GLP-1-(7-34)-amide & $\begin{array}{l}\text { Inhibits SIRT1 to stimulate pancreatic } \beta \text {-cell mass } \\
\text { expansion. }\end{array}$ & $(10)$ \\
\hline Melatonin & $\begin{array}{l}\text { Inhibits SIRT1 and has antitumor activity in osteosarcoma } \\
\text { cells. }\end{array}$ & $(31)$ \\
\hline Pitavastatin & $\begin{array}{l}\text { Increases SIRT1, eNOS, and CAT in streptozotocin-diabetic } \\
\text { mice; decreases endothelial senescence. }\end{array}$ & $(119)$ \\
\hline Quercetin & Increases SIRT1 in mouse epididymal adipose tissue. & $(36)$ \\
\hline Telmisartan & $\begin{array}{l}\text { Increases SIRT1 and AMPK phosphorylation in 3T3-L1 } \\
\text { adipocytes. }\end{array}$ & $(149)$ \\
\hline Vitamin D & $\begin{array}{l}\text { Upregulates SIRT1, rescues } \mathrm{H}_{2} \mathrm{O}_{2} \text {-induced SIRT1 reduction } \\
\text { in endothelial cells. }\end{array}$ & $(129)$ \\
\hline SRT2104 & $\begin{array}{l}\text { Activates SIRT1 and extends mean and maximal life } \\
\text { span of mice. }\end{array}$ & $(92)$ \\
\hline EX-527 & Acts as potent and selective inhibitor of SIRT1. & $(108)$ \\
\hline \multicolumn{3}{|l|}{ SIRT2 } \\
\hline Clasto-lactacystin $\beta$-lactone & $\begin{array}{l}\text { Inhibits } 26 \mathrm{~S} \text { proteasome, which results in increase } \\
\text { in SIRT2 protein in human cells. }\end{array}$ & $(37)$ \\
\hline Epoxomicin & Inhibits $26 \mathrm{~S}$ proteasome, resulting in increases in SIRT2. & $(37)$ \\
\hline AGK2 & $\begin{array}{l}\text { Inhibits SIRT } 2 \text {, thereby rescuing } \alpha \text {-synuclein-mediated } \\
\text { toxicity in models of Parkinson's disease. }\end{array}$ & $(120)$ \\
\hline \multicolumn{3}{|c|}{ 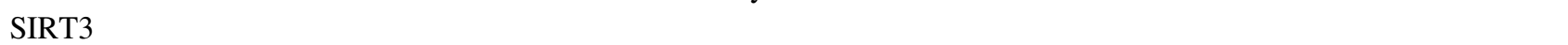 } \\
\hline Adjudin & $\begin{array}{l}\text { Upregulates SIRT3 levels in rodent cochlear hair cells, } \\
\text { exerting otoprotective effects. }\end{array}$ & $(130)$ \\
\hline Oroxylin A & $\begin{array}{l}\text { Increases mitochondrial SIRT3, which mediates } \\
\text { deacetylation of cyclophilin D in breast carcinoma. }\end{array}$ & $(174)$ \\
\hline Honokiol & $\begin{array}{l}\text { Blocks and reverses cardiac hypertrophy in mice by } \\
\text { activating SIRT3. }\end{array}$ & $(128)$ \\
\hline LC-0296 & $\begin{array}{l}\text { Inhibits SIRT3, cell proliferation, and promotes apoptosis } \\
\text { of head and neck squamous cell carcinoma cells. }\end{array}$ & $(2)$ \\
\hline $4^{\prime}$-Bromo-resveratrol & $\begin{array}{l}\text { Binds to SIRT3 structures, revealing a mechanism } \\
\text { for inhibition. }\end{array}$ & $(112)$ \\
\hline SDX-437 & Selectively inhibits SIRT3 > 100-fold over SIRT1. & $(123)$ \\
\hline \multicolumn{3}{|l|}{$\begin{array}{l}\text { SIRT4 } \\
\text { None reported }\end{array}$} \\
\hline \multicolumn{3}{|l|}{ SIRT5 } \\
\hline Suramin & $\begin{array}{l}\text { Binds to SIRT5, potentially inhibiting its deacetylase } \\
\text { activity. }\end{array}$ & $(147)$ \\
\hline GW5074 & Inhibits the desuccinylation activity of SIRT5. & $(153)$ \\
\hline \multicolumn{3}{|l|}{ SIRT6 } \\
\hline Quinazolinedione compounds & $\begin{array}{l}\text { Inhibit SIRT6, reduce TNF production, increase glucose } \\
\text { uptake, and increase H3K9 acetylation. }\end{array}$ & $(152)$ \\
\hline \multicolumn{3}{|l|}{ SIRT7 } \\
\hline \multicolumn{3}{|l|}{ Multiple SIRTs } \\
\hline D-glucose & $\begin{array}{l}\text { Decreases SIRTs 1-7 expression in microvascular } \\
\text { endothelial cells. Downregulates SIRT1, causing } \\
\text { increase in ROS and decrease in mitochondrial } \\
\text { antioxidant enzymes. }\end{array}$ & (102) \\
\hline
\end{tabular}


TABle 1. (CONTINUED)

\begin{tabular}{|c|c|c|}
\hline Modulators & Known actions & Ref. \\
\hline Nicotinamide (niacinamide) & $\begin{array}{l}\text { Prohibits proliferation and enhances chemosensitivity } \\
\text { of pancreatic cancer cells through inhibiting SIRT1 } \\
\text { and Ras/Akt pathways. }\end{array}$ & $(192)$ \\
\hline & Inhibits SIRT3 via competition with the cofactor $\mathrm{NAD}^{+}$. & $(50)$ \\
\hline Metformin & $\begin{array}{l}\text { Increases SIRT1 and reduces expression of UCP2 in rat liver } \\
\text { of type } 2 \text { diabetes mellitus with nonalcoholic fatty liver } \\
\text { disease. Also decreases SIRT5 in mouse hepatocytes } \\
\text { and liver. }\end{array}$ & $(179)$ \\
\hline Resveratrol & $\begin{array}{l}\text { Increases SIRT1 levels in RGC-5 retinal ganglion } \\
\text { cells and 3T3-L1 preadipocytes. Decreases } \\
\text { levels of SIRTs 3-4, as well as NAMPT } \\
\text { in wild-type adult zebrafish liver. }\end{array}$ & $(27,29)$ \\
\hline Trichostatin A & $\begin{array}{l}\text { Increases SIRTs } 2,4 \text {, and } 7 \text { in breast carcinoma cells } \\
\text { expressing human Er alpha (ESR } 1 \text { ) protein. }\end{array}$ & $(132)$ \\
\hline Valproic acid & $\begin{array}{l}\text { Increases SIRTs } 4 \text { and } 7 \text { in human Er alpha (ESR1) } \\
\text { protein-expressing breast cancer cells. }\end{array}$ & $(132)$ \\
\hline Pyrroloquinoline quinone & $\begin{array}{l}\text { Increases expression and activity of SIRTs } 1 \text { and } 3 \text { in } \\
\text { HepG } 2 \text { cells. }\end{array}$ & $(191)$ \\
\hline Tenovin- 1 and tenovin- 6 & $\begin{array}{l}\text { Inhibits the protein-deacetylating activities of SIRTs } \\
1 \text { and } 2 \text {. }\end{array}$ & $(78)$ \\
\hline Sirtinol and salermide & $\begin{array}{l}\text { Inhibit SIRTs } 1 \text { and } 2 \text {, resulting in increased cell death } \\
\text { and p53 acetylation in breast carcinoma cells. }\end{array}$ & $(124)$ \\
\hline Thieno[3,2-d]pyrimidine-6-carboxamide & Derivatives of this compound inhibit SIRTs $1-3$. & $(34)$ \\
\hline SRT1720 & $\begin{array}{l}\text { Activates SIRT1, but has potential to inhibit SIRT3 due } \\
\text { to binding to the crystal structure of SIRT3 in complex } \\
\text { with SRT1720. }\end{array}$ & $(113)$ \\
\hline
\end{tabular}

\footnotetext{
Although this list consolidates the current research on sirtuin modulators, it may not be comprehensive and the classification(s) may be subject to further research.

CAT, catalase; eNOS, endothelial nitric oxide synthase; $\mathrm{H}_{2} \mathrm{O}_{2}$, hydrogen peroxide; LDH, lactate dehydrogenase; NAD, nicotinamide adenine dinucleotide; NAMPT, nicotinamide phosphoribosyltransferase; NO, nitric oxide; ROS, reactive oxygen species; SIRT, sirtuin; TNF, tumor necrosis factor.
}

RPA194 and PAF53 $(28,162)$. This action seems to involve NAD-dependent stimulation of SIRT7, which in turn deacetylates RPA194 and PAF53, leading to increased RNA Pol I activity and rDNA transcription. These studies suggest that SIRT7 plays a pivotal role in cellular responses to energy levels and allows the cells to undergo a mechanism for the cessation of rDNA transcription in stress conditions. Recent research has also uncovered a role for SIRT7 in the regulation of mitochondrial homeostasis via deacetylation of GABP $\beta 1$, one of the subunits of a complex involved in regulating several key mitochondrial genes (137). It is unclear, however, if SIRT7 activity is a cause or effect of $\mathrm{NAD}^{+}$availability, and further research is needed to ascertain the nature of SIRT7's connection to NAD ${ }^{+}$and mediation of the cellular energy level. It has been demonstrated that SIRT7 is slightly downregulated in response to $\mathrm{H}_{2} \mathrm{O}_{2}$-induced oxidative stress in embryonal heartderived $\mathrm{H} 9 \mathrm{c} 2$ cells of rats (189). This study also found that this decrease was mitigated by pre-exposure to the SIRT activator resveratrol. This suggests that other oxidative stressrelated activities of resveratrol may be due to SIRT7 activity, at least in part, and that further work needs to be done to tease out the exact contributions of the other sirtuins to resveratrol's successes. Due to SIRT7 being a relatively recent subject of research, there is a lack of understanding about the substrates on which SIRT7 acts and therefore also the mechanisms by which it performs its various roles in the cell. However, preliminary studies suggest that it does play at least a small role in regulating the cell's response to oxidative stress (Fig. 2).

\section{Mechanistic Interactions Among Sirtuins in ARS}

As discussed above, each of the sirtuins has a distinct subcellular localization, which is important in rapidly sensing and responding to alterations in subcellular ROS within the mitochondria, nucleus, and cytoplasm. The toxic effects associated with altered levels of subcellular ROS are largely prevented by various antioxidants, many of which are regulated by sirtuins. Hence, sirtuins appear to be an integral part of an important cellular defense mechanism against oxidative stress and ROS formation. In Figure 2, the complexity of the cellular defense mechanism as it relates to the sirtuins can be seen. It is important to note that the subcellular localization of each of the sirtuins likely is a contributor to their ability to modulate ROS responses, and their interaction with ARS molecules can be seen in Figure 2 as well.

In general, research to date supports the notion that sirtuins play very important roles in maintaining proper cellular redox balance and in general seem to be protecting from the adverse effects of oxidative stress and associated diseases. This also suggests that the diseases involving redox imbalances may benefit from strategies aimed at sirtuin modulation. It is possible that while some conditions need targeting of specific sirtuins, others may need to target multiple sirtuins using pan activators. 
To gain insight into the potential mechanisms and interacting partners of sirtuin regulation, we performed an ingenuity pathway analysis (IPA) to generate an interaction network focusing on redox signaling. As shown in Figure 3, all seven sirtuins appeared to interact with important molecules, such as acetyl-CoA synthetase (AACS), protein kinase B (popularly known as AKT), ERK1/2, HCRTR2, histone 3, histone 4, insulin, NEGR1, NOLC1, PRKAA, SLC9A5, $\mathrm{SDH}$, and TBX15. Several of these molecules are known to be directly and/or indirectly linked with ARS. As an example, hyperactivation of AKT, a serine/threonine protein kinase, is known to occur in many cancer cell types. This raises metabolic activity in the mitochondria and inhibits FOXO transcriptional activity, resulting in greatly increased ROS levels, which sensitizes cancer cells to apoptosis induced by oxidative stimuli $(35,115)$.

Intriguingly, the IPA-generated sirtuin network showed interactions among sirtuins as well (Fig. 3). SIRT1 seems to interact directly with SIRTs 2, 6, and 7 as well as SIRT3, which further appears to interact with SIRTs 4 and 5. Also, SIRT1 has been found to regulate itself by several mechanisms, including initiating inhibition, degradation, ubiquitination, and stabilization. These interactions are defined based on experimental studies reported in the literature. For example, one direct link between SIRT1 and SIRT3 came from a report from Liu et al. where they have shown that SIRT1 inhibition decreases the expression of SIRT3 mRNA in TLR4stimulated primary culture human monocytes as well as in cultured mouse splenocytes (a model that mimics the initiation and adaptation stages of sepsis) (84). SIRT1 has also been shown to regulate the expression of SIRT6 mRNA. Kim et al. have shown that SIRT1 forms a complex with NRF1 and FOXO3a in the promoter region of SIRT6 to regulate the levels of SIRT6. Consequently, this regulates the deacetylation of H3K9 by SIRT6 and the promoter regions of several genes involved in negative regulation of glycolysis, triglyceride synthesis, and fat metabolism (72). This evidence, in addition to others cited above, suggests that on top of the individual antioxidant and ROS-related activities that the SIRTs perform, they may interact closely enough with each other to coregulate the levels of oxidative stress. The idea that sirtuins interact so closely with each other has not been fully explored to date. This may uncover how activation or inhibition of one sirtuin may affect the regulation of others and allow for deeper understanding of sirtuin-mediated redox homeostasis in the cell.

\section{Conclusion}

The fact that sirtuins play important roles in maintaining cellular homeostasis to keep the cells healthy makes them an ideal candidate to be studied in redox regulation. Maintenance of redox homeostasis is accomplished via feedback mechanisms functioning at the various levels of complexity mostly related to transcriptional modulation. As discussed above and summarized in Figures 4 and 5, the sirtuins are involved in regulating many of the key genes and molecules integral to redox homeostasis and oxidative stress mitigation. The majority of the mammalian sirtuins appear to have protective activities, antioxidant-promoting actions, and/or ROS-suppressive effects in the cell. However, SIRT4 appears to have dual roles and is the only sirtuin shown to induce ROS production. Overall, the apparent protective effects of sirtuins against oxidative stress support the theory that sirtuins could act synergistically via distinct mechanisms to enhance cellular homeostasis. This may serve as the mechanistic basis for the development and discovery of antioxidants and sirtuin modulators for the management of redox-related diseases. A list summarizing the chemical modulators of sirtuins with their known actions are detailed in Table 1. Further in-depth studies are required to ascertain and clarify the exact roles of each of the sirtuins, and to determine whether different sirtuins have functional redundancies, overlapping actions, or a dynamic equilibrium that may be important in regulating oxidative stress in the cell and as part of pathological manifestations. Given the interest in sirtuins as drug targets and their redox importance, the studies addressing these issues may provide therapeutic opportunities for the treatment of metabolic, age-related, and several other redox-related diseases.

\section{Acknowledgments}

This work was partially supported by funding from the National Institutes of Health (R01AR059130 and R01CA176748) and the Department of Veterans Affairs (VA Merit Review Awards I01BX001008 and I01CX001441; and a Research Career Scientist Award IK6BX003780 to N.A.).

\section{References}

1. Abdelmohsen K, Pullmann R, Jr., Lal A, Kim HH, Galban S, Yang X, Blethrow JD, Walker M, Shubert J, Gillespie DA, Furneaux H, and Gorospe M. Phosphorylation of HuR by Chk2 regulates SIRT1 expression. Mol Cell 25: 543-557, 2007.

2. Alhazzazi TY, Kamarajan P, Xu Y, Ai T, Chen L, Verdin E, and Kapila YL. A Novel sirtuin-3 inhibitor, LC-0296, inhibits cell survival and proliferation, and promotes apoptosis of head and neck cancer cells. Anticancer Res 36: 49-60, 2016.

3. Anderson KA, Huynh FK, Fisher-Wellman K, Stuart JD, Peterson BS, Douros JD, Wagner GR, Thompson JW, Madsen AS, Green MF, Sivley RM, Ilkayeva OR, Stevens RD, Backos DS, Capra JA, Olsen CA, Campbell JE, Muoio DM, Grimsrud PA, and Hirschey MD. SIRT4 is a lysine deacylase that controls leucine metabolism and insulin secretion. Cell Metab 25: 838-855.e15, 2017.

4. Ansari A, Rahman MS, Saha SK, Saikot FK, Deep A, and Kim KH. Function of the SIRT3 mitochondrial deacetylase in cellular physiology, cancer, and neurodegenerative disease. Aging Cell 16: 4-16, 2017.

5. Bae YS, Lee JH, Choi SH, Kim S, Almazan F, Witztum $\mathrm{JL}$, and Miller YI. Macrophages generate reactive oxygen species in response to minimally oxidized low-density lipoprotein: toll-like receptor 4- and spleen tyrosine kinase-dependent activation of NADPH oxidase 2. Circ Res 104: 210-218, 2009.

6. Bae YS, Oh H, Rhee SG, and Yoo YD. Regulation of reactive oxygen species generation in cell signaling. Mol Cells 32: 491-509, 2011.

7. Bai B, Vanhoutte PM, and Wang Y. Loss-of-SIRT1 function during vascular ageing: hyperphosphorylation mediated by cyclin-dependent kinase 5. Trends Cardiovasc Med 24: 81-84, 2014.

8. Bai W and Zhang X. Nucleus or cytoplasm? The mysterious case of SIRT1's subcellular localization. Cell Cycle 15: 3337-3338, 2016. 
9. Balestrieri ML, Rizzo MR, Barbieri M, Paolisso P, D'Onofrio N, Giovane A, Siniscalchi M, Minicucci F, Sardu C, D'Andrea D, Mauro C, Ferraraccio F, Servillo L, Chirico F, Caiazzo P, Paolisso G, and Marfella R. Sirtuin 6 expression and inflammatory activity in diabetic atherosclerotic plaques: effects of incretin treatment. Diabetes 64: 1395-1406, 2015.

10. Bastien-Dionne PO, Valenti L, Kon N, Gu W, and Buteau J. Glucagon-like peptide 1 inhibits the sirtuin deacetylase SirT1 to stimulate pancreatic beta-cell mass expansion. Diabetes 60: 3217-3222, 2011.

11. Bause AS, Matsui MS, and Haigis MC. The protein deacetylase SIRT3 prevents oxidative stress-induced keratinocyte differentiation. J Biol Chem 288: 36484-36491, 2013.

12. Beauharnois JM, Bolivar BE, and Welch JT. Sirtuin 6: a review of biological effects and potential therapeutic properties. Mol Biosyst 9: 1789-1806, 2013.

13. Bell EL, Emerling BM, Ricoult SJ, and Guarente L. SirT3 suppresses hypoxia inducible factor 1alpha and tumor growth by inhibiting mitochondrial ROS production. Oncogene 30: 2986-2996, 2011.

14. Betteridge DJ. What is oxidative stress? Metabolism 49: $3-8,2000$.

15. Blander $G$ and Guarente L. The Sir2 family of protein deacetylases. Annu Rev Biochem 73: 417-435, 2004.

16. Bobermin LD, Wartchow KM, Flores MP, Leite MC, Quincozes-Santos A, and Goncalves CA. Ammonia-induced oxidative damage in neurons is prevented by resveratrol and lipoic acid with participation of heme oxygenase 1. Neurotoxicology 49: 28-35, 2015.

17. Bosch-Presegue L and Vaquero A. The dual role of sirtuins in cancer. Genes Cancer 2: 648-662, 2011.

18. Braidy N, Guillemin GJ, Mansour H, Chan-Ling T, Poljak A, and Grant R. Age related changes in NAD+ metabolism oxidative stress and Sirt1 activity in wistar rats. PLoS One 6: e19194, 2011.

19. Brunet A, Sweeney LB, Sturgill JF, Chua KF, Greer PL, Lin Y, Tran H, Ross SE, Mostoslavsky R, Cohen HY, Hu LS, Cheng HL, Jedrychowski MP, Gygi SP, Sinclair DA, Alt FW, and Greenberg ME. Stress-dependent regulation of FOXO transcription factors by the SIRT1 deacetylase. Science 303: 2011-2015, 2004.

20. Buler M, Aatsinki SM, Izzi V, Uusimaa J, and Hakkola J. SIRT5 is under the control of PGC-1alpha and AMPK and is involved in regulation of mitochondrial energy metabolism. FASEB J 28: 3225-3237, 2014.

21. Burnett C, Valentini S, Cabreiro F, Goss M, Somogyvari M, Piper MD, Hoddinott M, Sutphin GL, Leko V, McElwee JJ, Vazquez-Manrique RP, Orfila AM, Ackerman D, Au C, Vinti G, Riesen M, Howard K, Neri C, Bedalov A, Kaeberlein M, Soti C, Partridge L, and Gems D. Absence of effects of Sir2 overexpression on lifespan in C. elegans and Drosophila. Nature 477: 482-485, 2011.

22. Cao C, Lu S, Kivlin R, Wallin B, Card E, Bagdasarian A, Tamakloe T, Wang WJ, Song X, Chu WM, Kouttab N, Xu A, and Wan Y. SIRT1 confers protection against UVBand $\mathrm{H} 2 \mathrm{O} 2$-induced cell death via modulation of $\mathrm{p} 53$ and JNK in cultured skin keratinocytes. J Cell Mol Med 13: 3632-3643, 2009.

23. Cao W, Hong Y, Chen H, Wu F, Wei X, and Ying W. SIRT2 mediates NADH-induced increases in Nrf2, GCL, and glutathione by modulating Akt phosphorylation in PC12 cells. FEBS Lett 590: 2241-2255, 2016.
24. Cao Z and Lindsay JG. The peroxiredoxin family: an unfolding story. Subcell Biochem 83: 127-147, 2017.

25. Chen B, Zang W, Wang J, Huang Y, He Y, Yan L, Liu J, and Zheng W. The chemical biology of sirtuins. Chem Soc Rev 44: 5246-5264, 2015.

26. Chen HY, Geng M, Hu YZ, and Wang JH. [Effects of baicalin against oxidative stress injury of SH-SY5Y cells by upregulating SIRT1]. Үао Хие Хие Вао 46: 1039-1044, 2011.

27. Chen S, Fan Q, Li A, Liao D, Ge J, Laties AM, and Zhang X. Dynamic mobilization of PGC-1alpha mediates mitochondrial biogenesis for the protection of RGC-5 cells by resveratrol during serum deprivation. Apoptosis 18: 786-799, 2013.

28. Chen S, Seiler J, Santiago-Reichelt M, Felbel K, Grummt I, and Voit R. Repression of RNA polymerase I upon stress is caused by inhibition of RNA-dependent deacetylation of PAF53 by SIRT7. Mol Cell 52: 303-313, 2013.

29. Chen S, Xiao X, Feng X, Li W, Zhou N, Zheng L, Sun Y, Zhang Z, and Zhu W. Resveratrol induces Sirt1-dependent apoptosis in 3T3-L1 preadipocytes by activating AMPK and suppressing AKT activity and survivin expression. J Nutr Biochem 23: 1100-1112, 2012.

30. Cheng HL, Mostoslavsky R, Saito S, Manis JP, Gu Y, Patel P, Bronson R, Appella E, Alt FW, and Chua KF. Developmental defects and p53 hyperacetylation in Sir2 homolog (SIRT1)-deficient mice. Proc Natl Acad Sci U S A 100: 10794-10799, 2003.

31. Cheng Y, Cai L, Jiang P, Wang J, Gao C, Feng H, Wang $\mathrm{C}$, Pan $\mathrm{H}$, and Yang Y. SIRT1 inhibition by melatonin exerts antitumor activity in human osteosarcoma cells. Eur J Pharmacol 715: 219-229, 2013.

32. Cheng Y, Ren X, Gowda AS, Shan Y, Zhang L, Yuan YS, Patel R, Wu H, Huber-Keener K, Yang JW, Liu D, Spratt TE, and Yang JM. Interaction of Sirt3 with OGG1 contributes to repair of mitochondrial DNA and protects from apoptotic cell death under oxidative stress. Cell Death Dis 4: e731, 2013.

33. D'Onofrio N, Servillo L, Giovane A, Casale R, Vitiello M, Marfella R, Paolisso G, and Balestrieri ML. Ergothioneine oxidation in the protection against high-glucose induced endothelial senescence: involvement of SIRT1 and SIRT6. Free Radic Biol Med 96: 211-222, 2016.

34. Disch JS, Evindar G, Chiu CH, Blum CA, Dai H, Jin L, Schuman E, Lind KE, Belyanskaya SL, Deng J, Coppo F, Aquilani L, Graybill TL, Cuozzo JW, Lavu S, Mao C, Vlasuk GP, and Perni RB. Discovery of thieno[3,2d]pyrimidine-6-carboxamides as potent inhibitors of SIRT1, SIRT2, and SIRT3. J Med Chem 56: 3666-3679, 2013.

35. Dolado I and Nebreda AR. AKT and oxidative stress team up to kill cancer cells. Cancer Cell 14: 427-429, 2008.

36. Dong J, Zhang X, Zhang L, Bian HX, Xu N, Bao B, and Liu J. Quercetin reduces obesity-associated ATM infiltration and inflammation in mice: a mechanism including AMPKalpha1/SIRT1. J Lipid Res 55: 363-374, 2014.

37. Dryden SC, Nahhas FA, Nowak JE, Goustin AS, and Tainsky MA. Role for human SIRT2 NAD-dependent deacetylase activity in control of mitotic exit in the cell cycle. Mol Cell Biol 23: 3173-3185, 2003.

38. Du J, Zhou Y, Su X, Yu JJ, Khan S, Jiang H, Kim J, Woo J, Kim JH, Choi BH, He B, Chen W, Zhang S, Cerione RA, Auwerx J, Hao Q, and Lin H. Sirt5 is a NADdependent protein lysine demalonylase and desuccinylase. Science 334: 806-809, 2011. 
39. Ferber EC, Peck B, Delpuech O, Bell GP, East P, and Schulze A. FOXO3a regulates reactive oxygen metabolism by inhibiting mitochondrial gene expression. Cell Death Differ 19: 968-979, 2012.

40. Finkel T, Deng CX, and Mostoslavsky R. Recent progress in the biology and physiology of sirtuins. Nature 460: 587-591, 2009.

41. Finley LW, Carracedo A, Lee J, Souza A, Egia A, Zhang J, Teruya-Feldstein J, Moreira PI, Cardoso SM, Clish CB, Pandolfi PP, and Haigis MC. SIRT3 opposes reprogramming of cancer cell metabolism through HIF1alpha destabilization. Cancer Cell 19: 416-428, 2011.

42. Fiskus W, Coothankandaswamy V, Chen J, Ma H, Ha K, Saenz DT, Krieger SS, Mill CP, Sun B, Huang P, Mumm JS, Melnick AM, and Bhalla KN. SIRT2 deacetylates and inhibits the peroxidase activity of peroxiredoxin-1 to sensitize breast cancer cells to oxidant stress-inducing agents. Cancer Res 76: 5467-5478, 2016.

43. Ford E, Voit R, Liszt G, Magin C, Grummt I, and Guarente L. Mammalian Sir2 homolog SIRT7 is an activator of RNA polymerase I transcription. Genes Dev 20: 10751080, 2006.

44. Frye RA. Phylogenetic classification of prokaryotic and eukaryotic Sir2-like proteins. Biochem Biophys Res Commun 273: 793-798, 2000.

45. Furukawa A, Tada-Oikawa S, Kawanishi S, and Oikawa $\mathrm{S}$. H2O2 accelerates cellular senescence by accumulation of acetylated p53 via decrease in the function of SIRT1 by NAD+ depletion. Cell Physiol Biochem 20: 45-54, 2007.

46. George J, Nihal M, Singh CK, Zhong W, Liu X, and Ahmad N. Pro-proliferative function of mitochondrial sirtuin deacetylase SIRT3 in human melanoma. J Invest Dermatol 136: 809-818, 2016.

47. Gomes P, Outeiro TF, and Cavadas C. Emerging role of sirtuin 2 in the regulation of mammalian metabolism. Trends Pharmacol Sci 36: 756-768, 2015.

48. Grabowska W, Sikora E, and Bielak-Zmijewska A. Sirtuins, a promising target in slowing down the ageing process. Biogerontology 18: 447-476, 2017.

49. Greiss S and Gartner A. Sirtuin/Sir2 phylogeny, evolutionary considerations and structural conservation. Mol Cells 28: 407-415, 2009.

50. Guan X, Lin P, Knoll E, and Chakrabarti R. Mechanism of inhibition of the human sirtuin enzyme SIRT3 by nicotinamide: computational and experimental studies. PLoS One 9: e107729, 2014.

51. Haigis MC, Deng CX, Finley LW, Kim HS, and Gius D. SIRT3 is a mitochondrial tumor suppressor: a scientific tale that connects aberrant cellular ROS, the Warburg effect, and carcinogenesis. Cancer Res 72: 2468-2472, 2012.

52. Haigis MC, Mostoslavsky R, Haigis KM, Fahie K, Christodoulou DC, Murphy AJ, Valenzuela DM, Yancopoulos GD, Karow M, Blander G, Wolberger C, Prolla TA, Weindruch R, Alt FW, and Guarente L. SIRT4 inhibits glutamate dehydrogenase and opposes the effects of calorie restriction in pancreatic beta cells. Cell 126: 941-954, 2006.

53. Haigis MC and Sinclair DA. Mammalian sirtuins: biological insights and disease relevance. Annu Rev Pathol 5: 253-295, 2010.

54. Halliwell B. Biochemistry of oxidative stress. Biochem Soc Trans 35: 1147-1150, 2007.

55. Hasegawa K, Wakino S, Yoshioka K, Tatematsu S, Hara Y, Minakuchi H, Washida N, Tokuyama H, Hayashi K, and Itoh H. Sirt1 protects against oxidative stress-induced renal tubular cell apoptosis by the bidirectional regulation of catalase expression. Biochem Biophys Res Commun 372: 51-56, 2008.

56. Hou KL, Lin SK, Chao LH, Hsiang-Hua Lai E, Chang CC, Shun CT, Lu WY, Wang JH, Hsiao M, Hong CY, and Kok SH. Sirtuin 6 suppresses hypoxia-induced inflammatory response in human osteoblasts via inhibition of reactive oxygen species production and glycolysis-A therapeutic implication in inflammatory bone resorption. Biofactors 43: 170-180, 2017.

57. Houtkooper RH, Pirinen E, and Auwerx J. Sirtuins as regulators of metabolism and healthspan. Nat Rev Mol Cell Biol 13: 225-238, 2012.

58. Hu DX, Liu XB, Song WC, and Wang JA. Roles of SIRT3 in heart failure: from bench to bedside. $J$ Zhejiang Univ Sci B 17: 821-830, 2016.

59. Hussain SP, Amstad P, He P, Robles A, Lupold S, Kaneko I, Ichimiya M, Sengupta S, Mechanic L, Okamura S, Hofseth LJ, Moake M, Nagashima M, Forrester KS, and Harris CC. p53-induced up-regulation of MnSOD and GPx but not catalase increases oxidative stress and apoptosis. Cancer Res 64: 2350-2356, 2004.

60. Ido Y, Duranton A, Lan F, Weikel KA, Breton L, and Ruderman NB. Resveratrol prevents oxidative stress-induced senescence and proliferative dysfunction by activating the AMPK-FOXO3 cascade in cultured primary human keratinocytes. PLoS One 10: e0115341, 2015.

61. Imai S, Armstrong CM, Kaeberlein M, and Guarente L. Transcriptional silencing and longevity protein Sir2 is an NAD-dependent histone deacetylase. Nature 403: 795-800, 2000.

62. Itoh K, Chiba T, Takahashi S, Ishii T, Igarashi K, Katoh Y, Oyake T, Hayashi N, Satoh K, Hatayama I, Yamamoto M, and Nabeshima Y. An Nrf2/small Maf heterodimer mediates the induction of phase II detoxifying enzyme genes through antioxidant response elements. Biochem Biophys Res Commun 236: 313-322, 1997.

63. Iwahara $\mathrm{T}$, Bonasio R, Narendra V, and Reinberg D. SIRT3 functions in the nucleus in the control of stressrelated gene expression. Mol Cell Biol 32: 5022-5034, 2012.

64. Jia G, Su L, Singhal S, and Liu X. Emerging roles of SIRT6 on telomere maintenance, DNA repair, metabolism and mammalian aging. Mol Cell Biochem 364: 345350, 2012.

65. Jing E, Emanuelli B, Hirschey MD, Boucher J, Lee KY, Lombard D, Verdin EM, and Kahn CR. Sirtuin-3 (Sirt3) regulates skeletal muscle metabolism and insulin signaling via altered mitochondrial oxidation and reactive oxygen species production. Proc Natl Acad Sci U S A 108: 14608-14613, 2011.

66. Jones DP and Sies H. The redox code. Antioxid Redox Signal 23: 734-746, 2015.

67. Kaeberlein M, McVey M, and Guarente L. The SIR2/3/4 complex and SIR2 alone promote longevity in Saccharomyces cerevisiae by two different mechanisms. Genes Dev 13: 2570-2580, 1999.

68. Kaufmann T, Kukolj E, Brachner A, Beltzung E, Bruno M, Kostrhon S, Opravil S, Hudecz O, Mechtler K, Warren $\mathrm{G}$, and Slade D. SIRT2 regulates nuclear envelope reassembly through ANKLE2 deacetylation. J Cell Sci 129: 4607-4621, 2016.

69. Kawahara TL, Michishita E, Adler AS, Damian M, Berber E, Lin M, McCord RA, Ongaigui KC, Boxer LD, Chang 
HY, and Chua KF. SIRT6 links histone H3 lysine 9 deacetylation to NF-kappaB-dependent gene expression and organismal life span. Cell 136: 62-74, 2009.

70. Kawahara TL, Rapicavoli NA, Wu AR, Qu K, Quake SR, and Chang HY. Dynamic chromatin localization of Sirt6 shapes stress- and aging-related transcriptional networks. PLoS Genet 7: e1002153, 2011.

71. Kendrick AA, Choudhury M, Rahman SM, McCurdy CE, Friederich M, Van Hove JL, Watson PA, Birdsey N, Bao J, Gius D, Sack MN, Jing E, Kahn CR, Friedman JE, and Jonscher KR. Fatty liver is associated with reduced SIRT3 activity and mitochondrial protein hyperacetylation. Biochem J 433: 505-514, 2011.

72. Kim HS, Xiao C, Wang RH, Lahusen T, Xu X, Vassilopoulos A, Vazquez-Ortiz G, Jeong WI, Park O, Ki SH, Gao B, and Deng CX. Hepatic-specific disruption of SIRT6 in mice results in fatty liver formation due to enhanced glycolysis and triglyceride synthesis. Cell Metab 12: 224-236, 2010.

73. Kiran S, Anwar T, Kiran M, and Ramakrishna G. Sirtuin 7 in cell proliferation, stress and disease: rise of the seventh sirtuin! Cell Signal 27: 673-682, 2015.

74. Kiran S, Chatterjee N, Singh S, Kaul SC, Wadhwa R, and Ramakrishna G. Intracellular distribution of human SIRT7 and mapping of the nuclear/nucleolar localization signal. FEBS J 280: 3451-3466, 2013.

75. Klotz LO, Sanchez-Ramos C, Prieto-Arroyo I, Urbanek P, Steinbrenner $\mathrm{H}$, and Monsalve M. Redox regulation of FoxO transcription factors. Redox Biol 6: 51-72, 2015.

76. Kobayashi A, Kang MI, Okawa H, Ohtsuji M, Zenke Y, Chiba T, Igarashi K, and Yamamoto M. Oxidative stress sensor Keap1 functions as an adaptor for Cul3-based E3 ligase to regulate proteasomal degradation of Nrf2. Mol Cell Biol 24: 7130-7139, 2004.

77. Krishnan J, Danzer C, Simka T, Ukropec J, Walter KM, Kumpf S, Mirtschink P, Ukropcova B, Gasperikova D, Pedrazzini T, and Krek W. Dietary obesity-associated Hiflalpha activation in adipocytes restricts fatty acid oxidation and energy expenditure via suppression of the Sirt2-NAD+ system. Genes Dev 26: 259-270, 2012.

78. Lain S, Hollick JJ, Campbell J, Staples OD, Higgins M, Aoubala M, McCarthy A, Appleyard V, Murray KE, Baker L, Thompson A, Mathers J, Holland SJ, Stark MJ, Pass G, Woods J, Lane DP, and Westwood NJ. Discovery, in vivo activity, and mechanism of action of a smallmolecule p53 activator. Cancer Cell 13: 454-463, 2008.

79. Lee J, Hong SW, Chae SW, Kim DH, Choi JH, Bae JC, Park SE, Rhee EJ, Park CY, Oh KW, Park SW, Kim SW, and Lee WY. Exendin-4 improves steatohepatitis by increasing Sirt1 expression in high-fat diet-induced obese C57BL/6J mice. PLoS One 7: e31394, 2012.

80. Liang F, Wang X, Ow SH, Chen W, and Ong WC. Sirtuin 5 is Anti-apoptotic and anti-oxidative in cultured SH-EP neuroblastoma cells. Neurotox Res 31: 63-76, 2017.

81. Lin ZF, Xu HB, Wang JY, Lin Q, Ruan Z, Liu FB, Jin W, Huang HH, and Chen X. SIRT5 desuccinylates and activates SOD1 to eliminate ROS. Biochem Biophys Res Commun 441: 191-195, 2013.

82. Liu B, Che W, Zheng C, Liu W, Wen J, Fu H, Tang K, Zhang J, and $\mathrm{Xu}$ Y. SIRT5: a safeguard against oxidative stress-induced apoptosis in cardiomyocytes. Cell Physiol Biochem 32: 1050-1059, 2013.

83. Liu R, Liu H, Ha Y, Tilton RG, and Zhang W. Oxidative stress induces endothelial cell senescence via downregulation of Sirt6. Biomed Res Int 2014: 902842, 2014.
84. Liu TF, Vachharajani V, Millet P, Bharadwaj MS, Molina AJ, and McCall CE. Sequential actions of SIRT1-RELBSIRT3 coordinate nuclear-mitochondrial communication during immunometabolic adaptation to acute inflammation and sepsis. J Biol Chem 290: 396-408, 2015.

85. Lu W, Zuo Y, Feng Y, and Zhang M. SIRT5 facilitates cancer cell growth and drug resistance in non-small cell lung cancer. Tumour Biol 35: 10699-10705, 2014.

86. Luo YX, Tang X, An XZ, Xie XM, Chen XF, Zhao $X$, Hao DL, Chen HZ, and Liu DP. SIRT4 accelerates Ang II-induced pathological cardiac hypertrophy by inhibiting manganese superoxide dismutase activity. Eur Heart J 38: 1389-1398, 2017.

87. Lushchak VI. Free radicals, reactive oxygen species, oxidative stress and its classification. Chem Biol Interact 224: 164-175, 2014.

88. Ma L, Liu X, Zhao Y, Chen B, Li X, and Qi R. Ginkgolide $B$ reduces LOX-1 expression by inhibiting Akt phosphorylation and increasing Sirt1 expression in oxidized LDLstimulated human umbilical vein endothelial cells. PLoS One 8: e74769, 2013.

89. Maillet A and Pervaiz S. Redox regulation of p53, redox effectors regulated by p53: a subtle balance. Antioxid Redox Signal 16: 1285-1294, 2012.

90. Margis R, Dunand C, Teixeira FK, and Margis-Pinheiro M. Glutathione peroxidase family - an evolutionary overview. FEBS J 275: 3959-3970, 2008.

91. McCarthy JT, Pelle E, Dong K, Brahmbhatt K, Yarosh D, and Pernodet N. Effects of ozone in normal human epidermal keratinocytes. Exp Dermatol 22: 360-361, 2013.

92. Mercken EM, Mitchell SJ, Martin-Montalvo A, Minor RK, Almeida M, Gomes AP, Scheibye-Knudsen M, Palacios HH, Licata JJ, Zhang Y, Becker KG, Khraiwesh H, Gonzalez-Reyes JA, Villalba JM, Baur JA, Elliott P, Westphal C, Vlasuk GP, Ellis JL, Sinclair DA, Bernier M, and de Cabo R. SRT2104 extends survival of male mice on a standard diet and preserves bone and muscle mass. Aging Cell 13: 787-796, 2014.

93. Merksamer PI, Liu Y, He W, Hirschey MD, Chen D, and Verdin E. The sirtuins, oxidative stress and aging: an emerging link. Aging (Albany NY) 5: 144-150, 2013.

94. Michan S and Sinclair D. Sirtuins in mammals: insights into their biological function. Biochem J 404: 1-13, 2007.

95. Michishita E, McCord RA, Berber E, Kioi M, Padilla-Nash H, Damian M, Cheung P, Kusumoto R, Kawahara TL, Barrett JC, Chang HY, Bohr VA, Ried T, Gozani O, and Chua KF. SIRT6 is a histone H3 lysine 9 deacetylase that modulates telomeric chromatin. Nature 452: 492-496, 2008.

96. Michishita E, McCord RA, Boxer LD, Barber MF, Hong $\mathrm{T}$, Gozani O, and Chua KF. Cell cycle-dependent deacetylation of telomeric histone H3 lysine K56 by human SIRT6. Cell Cycle 8: 2664-2666, 2009.

97. Michishita E, Park JY, Burneskis JM, Barrett JC, and Horikawa I. Evolutionarily conserved and nonconserved cellular localizations and functions of human SIRT proteins. Mol Biol Cell 16: 4623-4635, 2005.

98. Mitchell SJ, Martin-Montalvo A, Mercken EM, Palacios HH, Ward TM, Abulwerdi G, Minor RK, Vlasuk GP, Ellis JL, Sinclair DA, Dawson J, Allison DB, Zhang Y, Becker KG, Bernier M, and de Cabo R. The SIRT1 activator SRT1720 extends lifespan and improves health of mice fed a standard diet. Cell Rep 6: 836-843, 2014.

99. Morgan MJ and Liu ZG. Crosstalk of reactive oxygen species and NF-kappaB signaling. Cell Res 21: 103-115, 2011. 
100. Morigi M, Perico L, Rota C, Longaretti L, Conti S, Rottoli D, Novelli R, Remuzzi G, and Benigni A. Sirtuin 3-dependent mitochondrial dynamic improvements protect against acute kidney injury. J Clin Invest 125: 715-726, 2015.

101. Morris BJ. Seven sirtuins for seven deadly diseases of aging. Free Radic Biol Med 56: 133-171, 2013.

102. Mortuza R, Chen S, Feng B, Sen S, and Chakrabarti S. High glucose induced alteration of SIRTs in endothelial cells causes rapid aging in a p300 and FOXO regulated pathway. PLoS One 8: e54514, 2013.

103. Mostoslavsky R, Chua KF, Lombard DB, Pang WW, Fischer MR, Gellon L, Liu P, Mostoslavsky G, Franco S, Murphy MM, Mills KD, Patel P, Hsu JT, Hong AL, Ford E, Cheng HL, Kennedy C, Nunez N, Bronson R, Frendewey D, Auerbach W, Valenzuela D, Karow M, Hottiger MO, Hursting S, Barrett JC, Guarente L, Mulligan R, Demple B, Yancopoulos GD, and Alt FW. Genomic instability and aging-like phenotype in the absence of mammalian SIRT6. Cell 124: 315-329, 2006.

104. Murphy MP. How mitochondria produce reactive oxygen species. Biochem J 417: 1-13, 2009.

105. Nakagawa T and Guarente L. Sirtuins at a glance. J Cell Sci 124: 833-838, 2011.

106. Nakagawa T, Lomb DJ, Haigis MC, and Guarente L. SIRT5 Deacetylates carbamoyl phosphate synthetase 1 and regulates the urea cycle. Cell 137: 560-570, 2009.

107. Nakamura Y, Ogura M, Tanaka D, and Inagaki N. Localization of mouse mitochondrial SIRT proteins: shift of SIRT3 to nucleus by co-expression with SIRT5. Biochem Biophys Res Commun 366: 174-179, 2008.

108. Napper AD, Hixon J, McDonagh T, Keavey K, Pons JF, Barker J, Yau WT, Amouzegh P, Flegg A, Hamelin E, Thomas RJ, Kates M, Jones S, Navia MA, Saunders JO, DiStefano PS, and Curtis R. Discovery of indoles as potent and selective inhibitors of the deacetylase SIRT1. J Med Chem 48: 8045-8054, 2005.

109. Narayanan SV, Dave KR, Saul I, and Perez-Pinzon MA. Resveratrol preconditioning protects against cerebral ischemic injury via nuclear erythroid 2-related factor 2 . Stroke 46: 1626-1632, 2015.

110. Nasrin N, Wu X, Fortier E, Feng Y, Bare OC, Chen $\mathrm{S}$, Ren X, Wu Z, Streeper RS, and Bordone L. SIRT4 regulates fatty acid oxidation and mitochondrial gene expression in liver and muscle cells. J Biol Chem 285: 31995-32002, 2010.

111. Nemoto S, Fergusson MM, and Finkel T. SIRT1 functionally interacts with the metabolic regulator and transcriptional coactivator PGC-1 $\{$ alpha\}. J Biol Chem 280: 16456-16460, 2005.

112. Nguyen GT, Gertz M, and Steegborn C. Crystal structures of Sirt3 complexes with 4'-bromo-resveratrol reveal binding sites and inhibition mechanism. Chem Biol 20: 1375-1385, 2013.

113. Nguyen GT, Schaefer S, Gertz M, Weyand M, and Steegborn C. Structures of human sirtuin 3 complexes with ADP-ribose and with carba-NAD+ and SRT1720: binding details and inhibition mechanism. Acta Crystallogr D Biol Crystallogr 69: 1423-1432, 2013.

114. Nguyen T, Sherratt PJ, and Pickett CB. Regulatory mechanisms controlling gene expression mediated by the antioxidant response element. Annu Rev Pharmacol Toxicol 43: 233-260, 2003.

115. Nogueira V, Park Y, Chen CC, Xu PZ, Chen ML, Tonic I, Unterman T, Hay N. Akt determines replicative senes- cence and oxidative or oncogenic premature senescence and sensitizes cells to oxidative apoptosis. Cancer Cell 14: 458-470, 2008.

116. Oberdoerffer P, Michan S, McVay M, Mostoslavsky R, Vann J, Park SK, Hartlerode A, Stegmuller J, Hafner A, Loerch P, Wright SM, Mills KD, Bonni A, Yankner BA, Scully R, Prolla TA, Alt FW, and Sinclair DA. SIRT1 redistribution on chromatin promotes genomic stability but alters gene expression during aging. Cell 135: 907918, 2008.

117. Ogura M, Nakamura Y, Tanaka D, Zhuang X, Fujita Y, Obara A, Hamasaki A, Hosokawa M, and Inagaki N. Overexpression of SIRT5 confirms its involvement in deacetylation and activation of carbamoyl phosphate synthetase 1. Biochem Biophys Res Commun 393: 73-78, 2010.

118. Osborne B, Bentley NL, Montgomery MK, and Turner N. The role of mitochondrial sirtuins in health and disease. Free Radic Biol Med 100: 164-174, 2016.

119. Ota H, Eto M, Kano MR, Kahyo T, Setou M, Ogawa S, Iijima K, Akishita M, and Ouchi Y. Induction of endothelial nitric oxide synthase, SIRT1, and catalase by statins inhibits endothelial senescence through the Akt pathway. Arterioscler Thromb Vasc Biol 30: 2205-2211, 2010.

120. Outeiro TF, Kontopoulos E, Altmann SM, Kufareva I, Strathearn KE, Amore AM, Volk CB, Maxwell MM, Rochet JC, McLean PJ, Young AB, Abagyan R, Feany MB, Hyman BT, and Kazantsev AG. Sirtuin 2 inhibitors rescue alpha-synuclein-mediated toxicity in models of Parkinson's disease. Science 317: 516-519, 2007.

121. Pais TF, Szego EM, Marques O, Miller-Fleming L, Antas P, Guerreiro P, de Oliveira RM, Kasapoglu B, and Outeiro TF. The NAD-dependent deacetylase sirtuin 2 is a suppressor of microglial activation and brain inflammation. EMBO J 32: 2603-2616, 2013.

122. Pan H, Guan D, Liu X, Li J, Wang L, Wu J, Zhou J, Zhang W, Ren R, Zhang W, Li Y, Yang J, Hao Y, Yuan T, Yuan G, Wang H, Ju Z, Mao Z, Li J, Qu J, Tang F, and Liu GH. SIRT6 safeguards human mesenchymal stem cells from oxidative stress by coactivating NRF2. Cell Res 26: 190205, 2016.

123. Patel K, Sherrill J, Mrksich M, and Scholle MD. Discovery of SIRT3 inhibitors using SAMDI mass spectrometry. J Biomol Screen 20: 842-848, 2015.

124. Peck B, Chen CY, Ho KK, Di Fruscia P, Myatt SS, Coombes RC, Fuchter MJ, Hsiao CD, and Lam EW. SIRT inhibitors induce cell death and p53 acetylation through targeting both SIRT1 and SIRT2. Mol Cancer Ther 9: 844-855, 2010.

125. Perico L, Morigi M, and Benigni A. Mitochondrial sirtuin 3 and renal diseases. Nephron 134: 14-19, 2016.

126. Pesta D and Roden M. The janus head of oxidative stress in metabolic diseases and during physical exercise. Curr Diab Rep 17: 41, 2017.

127. Pham-Huy LA, He H, and Pham-Huy C. Free radicals, antioxidants in disease and health. Int J Biomed Sci 4: 8996, 2008.

128. Pillai VB, Samant S, Sundaresan NR, Raghuraman H, Kim G, Bonner MY, Arbiser JL, Walker DI, Jones DP, Gius D, and Gupta MP. Honokiol blocks and reverses cardiac hypertrophy in mice by activating mitochondrial Sirt3. Nat Commun 6: 6656, 2015.

129. Polidoro L, Properzi G, Marampon F, Gravina GL, Festuccia C, Di Cesare E, Scarsella L, Ciccarelli C, Zani BM, and Ferri C. Vitamin D protects human endothelial cells 
from $\mathrm{H}(2) \mathrm{O}(2)$ oxidant injury through the Mek/Erk-Sirt1 axis activation. $J$ Cardiovasc Transl Res 6: 221-231, 2013.

130. Quan Y, Xia L, Shao J, Yin S, Cheng CY, Xia W, and Gao WQ. Adjudin protects rodent cochlear hair cells against gentamicin ototoxicity via the SIRT3-ROS pathway. Sci Rep 5: 8181, 2015.

131. Radak Z, Koltai E, Taylor AW, Higuchi M, Kumagai S, Ohno H, Goto S, and Boldogh I. Redox-regulating sirtuins in aging, caloric restriction, and exercise. Free Radic Biol Med 58: 87-97, 2013.

132. Reid G, Metivier R, Lin CY, Denger S, Ibberson D, Ivacevic T, Brand $\mathrm{H}$, Benes V, Liu ET, and Gannon F. Multiple mechanisms induce transcriptional silencing of a subset of genes, including oestrogen receptor alpha, in response to deacetylase inhibition by valproic acid and trichostatin A. Oncogene 24: 4894-4907, 2005.

133. Richter C, Park JW, and Ames BN. Normal oxidative damage to mitochondrial and nuclear DNA is extensive. Proc Natl Acad Sci U S A 85: 6465-6467, 1988.

134. Rine J and Herskowitz I. Four genes responsible for a position effect on expression from HML and HMR in Saccharomyces cerevisiae. Genetics 116: 9-22, 1987.

135. Rosca MG, Vazquez EJ, Chen Q, Kerner J, Kern TS, and Hoppel CL. Oxidation of fatty acids is the source of increased mitochondrial reactive oxygen species production in kidney cortical tubules in early diabetes. Diabetes 61 : 2074-2083, 2012.

136. Roth M and Chen WY. Sorting out functions of sirtuins in cancer. Oncogene 33: 1609-1620, 2014.

137. Ryu D, Jo YS, Lo Sasso G, Stein S, Zhang H, Perino A, Lee JU, Zeviani M, Romand R, Hottiger MO, Schoonjans $\mathrm{K}$, and Auwerx J. A SIRT7-dependent acetylation switch of GABPbeta1 controls mitochondrial function. Cell Metab 20: 856-869, 2014.

138. Sablina AA, Budanov AV, Ilyinskaya GV, Agapova LS, Kravchenko JE, and Chumakov PM. The antioxidant function of the p53 tumor suppressor. Nat Med 11: 13061313, 2005.

139. Salvatori I, Valle C, Ferri A, and Carri MT. SIRT3 and mitochondrial metabolism in neurodegenerative diseases. Neurochem Int 2017 [Epub ahead of print]; DOI: 10.1016/ j.neuint.2017.04.012.

140. Santos L, Escande C, and Denicola A. Potential modulation of sirtuins by oxidative stress. Oxid Med Cell Longev 2016: 9831825, 2016.

141. Saso L and Firuzi O. Pharmacological applications of antioxidants: lights and shadows. Curr Drug Targets 15: 1177-1199, 2014.

142. Schafer FQ and Buettner GR. Redox environment of the cell as viewed through the redox state of the glutathione disulfide/glutathione couple. Free Radic Biol Med 30: 1191-1212, 2001.

143. Schieber $M$ and Chandel NS. ROS function in redox signaling and oxidative stress. Curr Biol 24: R453-R462, 2014.

144. Schirmer H, Pereira TC, Rico EP, Rosemberg DB, Bonan $\mathrm{CD}$, Bogo MR, and Souto AA. Modulatory effect of resveratrol on SIRT1, SIRT3, SIRT4, PGC1alpha and NAMPT gene expression profiles in wild-type adult zebrafish liver. Mol Biol Rep 39: 3281-3289, 2012.

145. Schlicker C, Gertz M, Papatheodorou P, Kachholz B, Becker CF, and Steegborn C. Substrates and regulation mechanisms for the human mitochondrial sirtuins Sirt3 and Sirt5. J Mol Biol 382: 790-801, 2008.
146. Schon EA. Mitochondrial genetics and disease. Trends Biochem Sci 25: 555-560, 2000.

147. Schuetz A, Min J, Antoshenko T, Wang CL, AllaliHassani A, Dong A, Loppnau P, Vedadi M, Bochkarev A, Sternglanz R, and Plotnikov AN. Structural basis of inhibition of the human NAD+-dependent deacetylase SIRT5 by suramin. Structure 15: 377-389, 2007.

148. Shinmura K. Effects of caloric restriction on cardiac oxidative stress and mitochondrial bioenergetics: potential role of cardiac sirtuins. Oxid Med Cell Longev 2013: 528935, 2013.

149. Shiota A, Shimabukuro M, Fukuda D, Soeki T, Sato H, Uematsu E, Hirata Y, Kurobe H, Sakaue H, Nakaya Y, Masuzaki H, and Sata M. Activation of AMPK-Sirt1 pathway by telmisartan in white adipose tissue: a possible link to anti-metabolic effects. Eur J Pharmacol 692: 8490, 2012.

150. Sies H and Jones DP. Oxidative stress. In: Encyclopedia of Stress, edited by Fink G. San Diego, CA: Academic Press, 2007, pp. 45-47.

151. Singh CK, Nihal M, and Ahmad N. Histone deacetylase inhibitory approaches for the management of osteoarthritis. Am J Pathol 186: 2555-2558, 2016.

152. Sociali G, Galeno L, Parenti MD, Grozio A, Bauer I, Passalacqua M, Boero S, Donadini A, Millo E, Bellotti M, Sturla L, Damonte P, Puddu A, Ferroni C, Varchi G, Franceschi C, Ballestrero A, Poggi A, Bruzzone S, Nencioni A, and Del Rio A. Quinazolinedione SIRT6 inhibitors sensitize cancer cells to chemotherapeutics. Eur J Med Chem 102: 530-539, 2015.

153. Suenkel B, Fischer F, and Steegborn C. Inhibition of the human deacylase sirtuin 5 by the indole GW5074. Bioorg Med Chem Lett 23: 143-146, 2013.

154. Sundaresan NR, Gupta M, Kim G, Rajamohan SB, Isbatan A, and Gupta MP. Sirt3 blocks the cardiac hypertrophic response by augmenting Foxo3a-dependent antioxidant defense mechanisms in mice. J Clin Invest 119: 27582771, 2009.

155. Tan M, Li S, Swaroop M, Guan K, Oberley LW, and Sun Y. Transcriptional activation of the human glutathione peroxidase promoter by p53. J Biol Chem 274: 12061-12066, 1999.

156. Tao R, Vassilopoulos A, Parisiadou L, Yan Y, and Gius D. Regulation of MnSOD enzymatic activity by Sirt3 connects the mitochondrial acetylome signaling networks to aging and carcinogenesis. Antioxid Redox Signal 20: 1646-1654, 2014.

157. Tarantino G, Finelli C, Scopacasa F, Pasanisi F, Contaldo F, Capone D, and Savastano S. Circulating levels of sirtuin 4 , a potential marker of oxidative metabolism, related to coronary artery disease in obese patients suffering from NAFLD, with normal or slightly increased liver enzymes. Oxid Med Cell Longev 2014: 920676, 2014.

158. TenNapel MJ, Lynch CF, Burns TL, Wallace R, Smith BJ, Button A, and Domann FE. SIRT6 minor allele genotype is associated with $>5$-year decrease in lifespan in an aged cohort. PLoS One 9: e115616, 2014.

159. Tennen RI, Bua DJ, Wright WE, and Chua KF. SIRT6 is required for maintenance of telomere position effect in human cells. Nat Commun 2: 433, 2011.

160. Tennen RI and Chua KF. Chromatin regulation and genome maintenance by mammalian SIRT6. Trends Biochem Sci 36: 39-46, 2011.

161. Toiber D, Sebastian C, and Mostoslavsky R. Characterization of nuclear sirtuins: molecular mechanisms and 
physiological relevance. Handb Exp Pharmacol 206: 189_ 224, 2011.

162. Tsai YC, Greco TM, Boonmee A, Miteva Y, and Cristea IM. Functional proteomics establishes the interaction of SIRT7 with chromatin remodeling complexes and expands its role in regulation of RNA polymerase I transcription. Mol Cell Proteomics 11: 60-76, 2012.

163. Vakhrusheva O, Smolka C, Gajawada P, Kostin S, Boettger T, Kubin T, Braun T, and Bober E. Sirt7 increases stress resistance of cardiomyocytes and prevents apoptosis and inflammatory cardiomyopathy in mice. Circ Res 102: 703-710, 2008.

164. Van Meter M, Mao Z, Gorbunova V, and Seluanov A. Repairing split ends: SIRT6, mono-ADP ribosylation and DNA repair. Aging (Albany NY) 3: 829-835, 2011.

165. Vaquero A and Reinberg D. Calorie restriction and the exercise of chromatin. Genes Dev 23: 1849-1869, 2009.

166. Verdin E, Hirschey MD, Finley LW, and Haigis MC. Sirtuin regulation of mitochondria: energy production, apoptosis, and signaling. Trends Biochem Sci 35: 669675, 2010.

167. Walsh ME, Shi Y, and Van Remmen H. The effects of dietary restriction on oxidative stress in rodents. Free Radic Biol Med 66: 88-99, 2014.

168. Wang F, Nguyen M, Qin FX, and Tong Q. SIRT2 deacetylates FOXO3a in response to oxidative stress and caloric restriction. Aging Cell 6: 505-514, 2007.

169. Wang XX, Wang XL, Tong MM, Gan L, Chen H, Wu SS, Chen JX, Li RL, Wu Y, Zhang HY, Zhu Y, Li YX, He JH, Wang M, and Jiang W. SIRT6 protects cardiomyocytes against ischemia/reperfusion injury by augmenting FoxO3alpha-dependent antioxidant defense mechanisms. Basic Res Cardiol 111: 13, 2016.

170. Wang Y, Zhu Y, Xing S, Ma P, and Lin D. SIRT5 prevents cigarette smoke extract-induced apoptosis in lung epithelial cells via deacetylation of FOXO3. Cell Stress Chaperones 20: 805-810, 2015.

171. Wang YP, Zhou LS, Zhao YZ, Wang SW, Chen LL, Liu LX, Ling ZQ, Hu FJ, Sun YP, Zhang JY, Yang C, Yang Y, Xiong Y, Guan KL, and Ye D. Regulation of G6PD acetylation by SIRT2 and KAT9 modulates NADPH homeostasis and cell survival during oxidative stress. EMBO J 33: 1304-1320, 2014.

172. Watroba $\mathrm{M}$ and Szukiewicz D. The role of sirtuins in aging and age-related diseases. Adv Med Sci 61: 52-62, 2016.

173. Webster BR, Lu Z, Sack MN, and Scott I. The role of sirtuins in modulating redox stressors. Free Radic Biol Med 52: 281-290, 2012.

174. Wei L, Zhou Y, Dai Q, Qiao C, Zhao L, Hui H, Lu N, and Guo QL. Oroxylin A induces dissociation of hexokinase II from the mitochondria and inhibits glycolysis by SIRT3mediated deacetylation of cyclophilin D in breast carcinoma. Cell Death Dis 4: e601, 2013.

175. Weidinger A and Kozlov AV. Biological activities of reactive oxygen and nitrogen species: oxidative stress versus signal transduction. Biomolecules 5: 472-484, 2015.

176. Wilking MJ, Singh C, Nihal M, Zhong W, and Ahmad N. SIRT1 deacetylase is overexpressed in human melanoma and its small molecule inhibition imparts anti-proliferative response via p53 activation. Arch Biochem Biophys 563: 94-100, 2014.

177. Winnik S, Gaul DS, Siciliani G, Lohmann C, Pasterk L, Calatayud N, Weber J, Eriksson U, Auwerx J, van Tits LJ, Luscher TF, and Matter CM. Mild endothelial dysfunction in Sirt3 knockout mice fed a highcholesterol diet: protective role of a novel C/EBP-betadependent feedback regulation of SOD2. Basic Res Cardiol 111: 33, 2016.

178. $\mathrm{Wu} \mathrm{YT}, \mathrm{Wu} \mathrm{SB}$, and Wei YH. Roles of sirtuins in the regulation of antioxidant defense and bioenergetic function of mitochondria under oxidative stress. Free Radic Res 48: 1070-1084, 2014.

179. Xu J, Li N, Wang J, Zhang C, Ding S, Jiao Y, and Zhang J. [Effect of metformin on the expression of SIRT1 and UCP2 in rat liver of type 2 diabetes mellitus and nonalcoholic fatty liver]. Zhong Nan Da Хие Хие Вао Yi Хие Ban 38: 882-887, 2013.

180. Xu MF, Xiong YY, Liu JK, Qian JJ, Zhu L, and Gao J. Asiatic acid, a pentacyclic triterpene in Centella asiatica, attenuates glutamate-induced cognitive deficits in mice and apoptosis in SH-SY5Y cells. Acta Pharmacol Sin 33: 578-587, 2012.

181. Xu Y, Li F, Lv L, Li T, Zhou X, Deng CX, Guan KL, Lei QY, and Xiong Y. Oxidative stress activates SIRT2 to deacetylate and stimulate phosphoglycerate mutase. Cancer Res 74: 3630-3642, 2014.

182. Xue F, Huang JW, Ding PY, Zang HG, Kou ZJ, Li T, Fan J, Peng ZW, and Yan WJ. Nrf2/antioxidant defense pathway is involved in the neuroprotective effects of Sirt1 against focal cerebral ischemia in rats after hyperbaric oxygen preconditioning. Behav Brain Res 309: $1-8,2016$.

183. Yang L, Ma X, He Y, Yuan C, Chen Q, Li G, and Chen X. Sirtuin 5: a review of structure, known inhibitors and clues for developing new inhibitors. Sci China Life Sci 60: 249256, 2017.

184. Yang X, Park SH, Chang HC, Shapiro JS, Vassilopoulos A, Sawicki KT, Chen C, Shang M, Burridge PW, Epting CL, Wilsbacher LD, Jenkitkasemwong S, Knutson M, Gius D, and Ardehali H. Sirtuin 2 regulates cellular iron homeostasis via deacetylation of transcription factor NRF2. J Clin Invest 127: 1505-1516, 2017.

185. Young IS and Woodside JV. Antioxidants in health and disease. J Clin Pathol 54: 176-186, 2001.

186. Yu J and Auwerx J. Protein deacetylation by SIRT1: an emerging key post-translational modification in metabolic regulation. Pharmacol Res 62: 35-41, 2010.

187. Yu J, Wu Y, and Yang P. High glucose-induced oxidative stress represses sirtuin deacetylase expression and increases histone acetylation leading to neural tube defects. J Neurochem 137: 371-383, 2016.

188. Yu SS, Cai Y, Ye JT, Pi RB, Chen SR, Liu PQ, Shen XY, and Ji Y. Sirtuin 6 protects cardiomyocytes from hypertrophy in vitro via inhibition of NF-kappaB-dependent transcriptional activity. $\mathrm{Br} J$ Pharmacol 168: 117-128, 2013.

189. Yu W, Fu YC, Zhou XH, Chen CJ, Wang X, Lin RB, and Wang W. Effects of resveratrol on $\mathrm{H}(2) \mathrm{O}(2)$-induced apoptosis and expression of SIRTs in H9c2 cells. J Cell Biochem 107: 741-747, 2009.

190. Zhang $\mathrm{H}$ and Forman HJ. Reexamination of the electrophile response element sequences and context reveals a lack of consensus in gene function. Biochim Biophys Acta 1799: 496-501, 2010.

191. Zhang J, Meruvu S, Bedi YS, Chau J, Arguelles A, Rucker $\mathrm{R}$, and Choudhury M. Pyrroloquinoline quinone increases the expression and activity of Sirt 1 and -3 genes in HepG2 cells. Nutr Res 35: 844-849, 2015. 
192. Zhang JG, Zhao G, Qin Q, Wang B, Liu L, Liu Y, Deng SC, Tian K, and Wang CY. Nicotinamide prohibits proliferation and enhances chemosensitivity of pancreatic cancer cells through deregulating SIRT1 and Ras/Akt pathways. Pancreatology 13: 140-146, 2013.

Address correspondence to: Dr. Nihal Ahmad Department of Dermatology University of Wisconsin 1300 University Avenue Madison, WI 53706

E-mail:nahmad@wisc.edu

Date of first submission to ARS Central, July 17, 2017; date of final revised submission, September 1, 2017; date of acceptance, September 7, 2017.

$\begin{aligned} & \text { Abbreviations Used } \\ & \text { 4-HNE }= \text { 4-hydroxynonenal } \\ & 8 \text {-oxoG }=8 \text {-oxo-7,8-dihydroguanine } \\ & \mathrm{ADP}=\text { adenosine diphosphate } \\ & \mathrm{Ang} \mathrm{II}=\text { angiotensin II } \\ & \mathrm{ARE}=\text { antioxidant response element } \\ & \mathrm{ARS}=\text { antioxidant and redox signaling } \\ & \mathrm{CAT}=\text { catalase } \\ & \mathrm{CHK} 2=\text { checkpoint kinase } 2 \\ & \mathrm{CPS} 1=\text { carbamoyl phosphate synthetase } \\ & \mathrm{CUL} 3=\text { cullin } 3 \\ & \mathrm{DNA}=\text { deoxy acid } \\ & \mathrm{ERE}=\text { electrophilic response element } \\ & \mathrm{FOXO}=\text { class O of forkhead box transcription } \\ & \text { factors } \\ & \mathrm{G} 6 \mathrm{PD}=\text { glucose } 6 \text {-phosphate dehydrogenase }\end{aligned}$

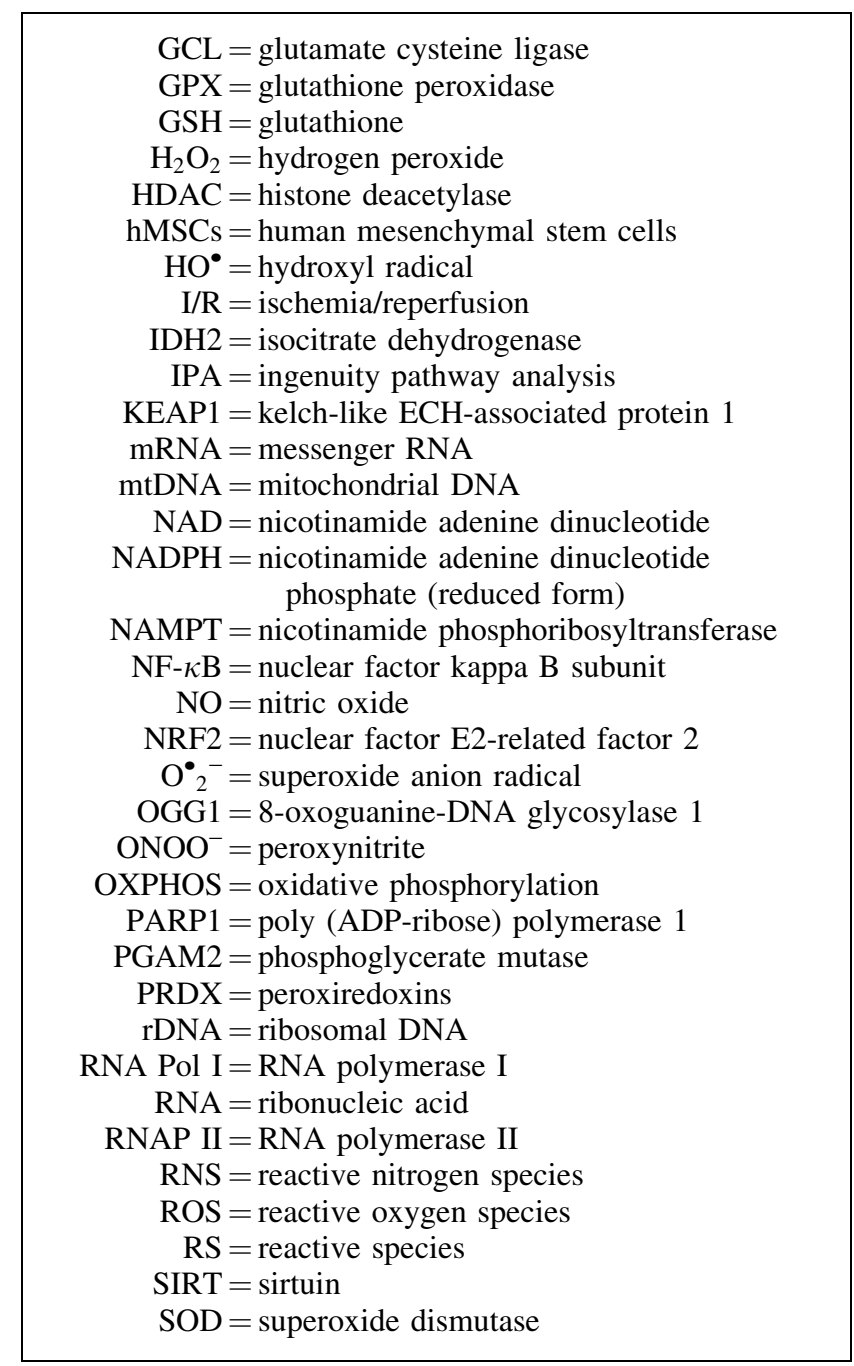

